\title{
Network-Agent systems dynamic modelling: A guide for sport science
}

\author{
Chul-wook Park \& Seonjin Kim* \\ Seoul National University Institute of Sport Science
}

\begin{abstract}
[Purpose] The primary purpose of this study is to show and guide how to construct a large variety of behaviors in systems dynamic for sport science. [Methods] By applying a simple algorithm to networked agents, which could, conceivably, offer a straightforward way out of the complexity, computational mechanism which along with its dynamics (payoff, failure, and strategy) involved. [Results] The model starts with the probability that systemic risk potential such as failure spreads. Even in a very random structure commonly used in sports field, propagation of the potential is guaranteed by an arbitrary network property of a set of elements. Despite the intensive systemic potential, the opposite type of potential like absence of failure could also be driven when there has been a strong investment in protection through a heuristically evolved protection level. [Conclusion] The implementation still needs to be polished against what happens in the real sports world, but in general, applied conceptual principle and methodological techniques behind the network-agent based mechanisms could be useful for researchers those who need to use systemes dynamic to guard in sport science.
\end{abstract}

Key Words: Random network, agent-based model, systems dynamic, risk, heuristics

\section{서 론}

스포츠 현장은 매우 체계적이고 역동적이지만 복잡하 다(Bernstein, 19667; Haken, 2012). 개인들이 마주하 는 실질적인 정보는 실시간 변하고 있으며, 그 현상은 상 호작용적으로 끊임없이 진화한다(Pacheco et al, 2006). 이에 스포츠 과학은 정확한 가설을 검증하고 신뢰할 수 있는 결론을 도출하기 위해 노력하고 있다. 또한, 전례 없 는 통찰을 얻기 위해서 다양한 접근의 분석(Forgas, 1995; Park, 2020)을 시도하고 있다. 하지만, 근본적인 동인을 찾고 결과를 예측하는 방법은 기본적으로 개발되 어있는 도구 및 이론에만 의존하고 있으며, 대부분 그 체계 를 구성하는 개인(요소 또는 구성원)과 그들의 연결에만 관심을 두고 있는 실정이다(Choi et al., 2011; Moody, 2004). 특히, 스포츠 과학 연구(i.e., 실험연구, 설문조

논문 투고일 : 2020. 05. 04.

논문 수정일 : 2020. 07. 15 .

게재 확정일 : 2020. 08. 07.

* 교신저자 : 김선진(seonkim@snu.ac.kr).
사)의 방법론적 측면에서 실험자의 조작과는 다르게 개 입하는 참가자들의 문화적 배경, 일시적 분위기, 연구 윤 리와 타당성 (Shariff et al., 2016), 심지어는 여전히 제 한적일 수밖에 없는 자료 수집의 양과 시간(samples and simulations)은 심리/행동적 변화의 창발을 보다 객 관적으로 설명하기에 많은 무리를 남기고 있다(Abbott, 1988; Narizuka \& Yamazaki, 2018).

우리가 직면하는 스포츠는 개인과 주변 환경이 상호 연결된 상호작용에 따라 그 상황은 물론 개인 행동의 결 과가 달라지기에 이를 인식하지 못하는 방법과 도구는 합 리성을 결여하고 편향될 수 밖에 없다(Horn \& Newton, 2019). 따라서 행동에 영향을 미치는 수많은 요소 및 변 수, 다차원적인 구성 요소의 발달 및 체계적 변화를 고려 하는 생태학적이고 역동적인 접근을 통해 행동의 원인과 결과를 설명할 수 있어야 할 것이다(Park, 2018). 이에 본 연구에서는 이미 수학, 물리학, 생물학과 같은 기초과 학(Boza, et al., 2019; Hajihashemi \& Samani, 2019; Railsback \& Grimm, 2019)은 물론, 심리학 (Goldstone \& Janssen, 2005; Jackson, et al., 2017) 
경제학(Tesfatsion \& Judd, 2006), 사회학(Bruch \& Atwell, 2015), 정치학(Cederman, 2005) 및 일부 응용 과학(Beer, 1995; Wooldridge, 2003) 등에서 활발히 활 용되고 있으나, 국내 스포츠 과학에서 쉽게 소개되지 못 하고 있는 네트워크-개인 알고리즘을 소개하고, 스포츠 현장의 잠재적 위험(Clemente et al., 2016)에 대한 보 호 기전을 구축함으로써 체계 역학(systems dynamics) 모형의 현장 적용 가능성을 시사하고자 한다.

네트워크 전반의 잠재적 위험: 인체의 많은 요소는 상호 연결한다(Kugler et al., 1980). 움직임을 일으키 기 위해 신경, 근육과 같은 자율적인 변인들은 스스로 기 능적 네트워크 구조를 형성하는데(Sussillo et al., 2015), 이 중 어느 하나라도 방해를 받으면 그 구조의 안 정성을 깨뜨리는 원인이 된다(Griller, 1975). 단순히 움 직임뿐만 아니라 운동 경기, 스포츠 산업에 이르기까지 우리는 어떤 요소 또는 사건으로 인해 유발된 아주 작은 문제가 그 체계의 기능에 심각한 충격을 주는 것을 종종 목격한다(Thacker et al., 2003). 하나 또는 몇몇 부분 의 문제(i.e., failure)가 다른 부분의 계단식 실패 (casecading failure)를 초래하는 현상은 비단 일반 사회 에서만 일어나고 있는 일(i.e., coronal virus at 2019, financial cirsis at 2008)이 아닐 것이다. 상호연계 (interconnectedness)한 구성 요소 간의 불안정 특성에 서 발생하는 이러한 체계적 위험(systemic risk)은 큰 재 난의 원인으로 인식(Leduc et al., 2017)되고 있는데, 사 회의 축소판(Jarvie, 2013)이라 일컬어지기도 하는 스포 츠도 예외일 수는 없다(예: 폼의 변화, 선수의 부상, 팀의 패배, 나아가서 구단 및 산업의 몰락 등). 특히, 각 요소 (node) 간 상호작용 또는 그들의 연계(linkages)가 높은 근·신경 및 스포츠 네트워크에서 이러한 잠재성의 확산은 상황에 따라 다양한 양상으로 전개(network risk; Pacheco et all, 2006)되며 기하급수적 (Trimmer et al., 2011)인 것으로 알려져 있다.

이에, 그 영향력을 정량화하고 현상을 왜곡시키는 기 전을 이해하려는 노력이 이루어지고 있다. 문제(i.e., failure, injury)를 일으키는 잘못된 요인의 확산 (propagation)과 같은 위험(systemic risk)의 특정 양상 을 식별하고 이에 대한 보호(protection) 기전을 구축하 려는 새로운 차원의 시도가 일어나고 있는 것이다 (Dehmamy et al., 2018; Grove et al.,1991; Lusher et al., 2010; Park, 2020). 선행된 연구들에서는 그 잠 재성을 일으키는 기전을 체계적으로 프로그래밍 함으로 써 어떤 시점에서 개인의 능력 및 역량에 관계없이(또는 관계하여) 체계의 불안정성을 유발하거나 전체 체계를 붕괴시킬 수 있는 특정 형태의 원인들을 구조화해 볼 것 을 권장한다. 이를 위해서, 각 개인의 내성 (robustness), 잠재적 문제 요인의 전파(spreading), 그에 대한 보호 (protection flows)와 집단행동 (collective behavior) 등 상호 연관하고 있는 구성 요소의 복잡성이 실제 현상을 어떻게 일으키는지를 보여주는 계산 시뮬레이션을 제안 한다(Pastor-Satorras et al., 2015). 특히, 무작위하게 형성된 연결(random graph theory: Erods \& Renyi, 1959)이 사회현상 (Barabási \& Albert, 1999)뿐 아니라 근·신경 및 스포츠 네트워크의 구조와 각 요소 간 소통을 이해하기 위해서도 매우 적합한 것으로 보고하고 있다 (Robins et al., 2007; Ribeiro et al., 2017).

모방과 개인-기반 모형: 일반적으로 우리는 다양한 상황에서 적절한 행동을 일으키는 일련의 학습 기전을 발 전시키고 그 기전은 당면한 자극에 감각적으로 편향한다 (Tversky \& Kahneman, 1985). 더구나, 근·신경의 기 능적 단위(i.e., perception-action)로서 움직임, 또는 긴 밀한 상호작용 현상(i.e., team spirit)으로서 스포츠와 같이 역동적인 구조를 형성하는 네트워크 특성 (Narizuka \& Yamazaki, 2018)은 일단 시작되면 각 단 계가 전 단계로 인하여 발현되고 그 결과 종국까지 계열 적으로 증폭하는데, 이는 주변 요소들에 대한 반응으로 행동을 조절하는 것과 관계된 학습 규칙의 모방 (imitation)과 탐색 (exploration) 때문으로 해석되고 있 다(Miller \& Dollard, 1941). 이는 스스로 의사결정 하 는 각 요소의 정교한 행동적 적응은 단순히 유전된 특질 이기보다 성공적인 행동들이 다른 개인들에 의해 모방되 고 학습을 통해 전략적으로 전파(cultural evolution)하 는 과정 (Fawcett et al., 2012)이라는 측면으로, 어떻게 이러한 행동의 변화와 적응이 주어진 환경, 물리, 제도적 도구(Putnam, 2000)와 상호작용적으로 관계하는지 고 려해야 할 필요가 있다 $(\mathrm{Lin}, 2017)$ 는 것이다.

이와 관련해서, 미시적 수준(micro-scale)의 개인 상 호작용과 거시적 수준(macro-scale)의 구조가 공존하는 진화적 특질이 적용된 개인-기반 모델(agent-based model)이 이러한 상호작용 관계를 파악하기에 적합한 것 
으로 알려져 있다(Hulme et al., 2019). 개인-기반 모델 은 행동적 알고리즘을 네트워크 역학에 통합함으로써 행 동 양식에 대한 자연스러운 설명을 제공할 수 있으며, 창 발(emergent) 현상을 포착할 수 있어 적응의 현실적인 이해를 가능하게 한다(Bonabeau, 2002). 매 시점, 개인 (i.e., molecules, cells, athletes)을 둘러싼 이웃의 계획 이 결정적 요소로서 변수의 상태를 시·계열적으로 다루 고, 구성 요소들이 상향식(bottom up)으로 발생하는 자 치적인 개인(autonomous agents)을 대표함에 따라 그 들 행동의 실제적 상태가 더욱더 현실적인 의미를 부여할 수 있다(Reynolds, 1987). 특히, 실제 개인행동(i.e., traninig habbits, tendency to seek healthcare)을 모 방하고 탐색하는 사회 학습 및 문화적 진화 기전을 포함 할 수 있으므로 인위적으로 고안된 체계에서 가질 수 있는 상호작용에 기반한 합리적인 의사결정을 효과적으로 관찰 하게 할 수 있도록 한다(Oliva, 2016). 그리고 이러한 이 유에서 스포츠 현장에서도 적용을 시도하고 있다. 예를 들 어, 건강(i.e., 신체활동, 비만) 관련 연구에서 전통적인 통계적 접근법(i.e., regression analysis)은 체계에 영향 을 미치는 개인 간 전염성(contagious between individuals)을 구분할 수 없음을 인정하고 에이전트 기 반 네트워크 모형을 적용 하였다(Shoham et al., 2012). 스포츠 상해와 같은 위험을 예방하기 위해서는 개별 요인 의 인과적 영향을 분리하려 하기보다는 '상호 작용하는 네트워크상의 요인(Bittencourt et al., 2016)'사이에서 발생하는 복잡한 관계를 이해해야 한다는 것을 인정하고 (Hulme \& Finch, 2015) 네트워크-에이전트 기반의 시 뮬레이션을 적용 하였다.

연구문제: 하지만, 실제로 네트워크화한 근·신경 및 스포츠 개인 잠재성의 이해를 뒷받침하는 알고리즘과 기 전의 형성은 여전히 진행 중인 작업이다. 체계적인 위험 및 인지적인 편향(systemic risk, cognitive bias)에 관 한 진화론적 설명은 개인적 조건에 따른 선택과 기회, 영 역의 구조와 그들 능력의 강화(Powell et al., 2005)를 설명할 수 있어야 한다. 어떻게 의사결정자가 자신의 역 량에 대한 편향된 추정에 제약되어 있는지, 지각된 자원 의 가치에 따라 최적의 전략을 변경하는지를 보여줄 수도 있어야 한다(Marshall et al., 2013). 특히, 움직임 및 스포츠 현장과 같이 복잡한 체계 (complex system)에서 다른 전략(strategy)에 노출됨으로써 다른 의사결정을
일으키는 편향(behavioral bias)을 제시할 수도 있어야 할 것이다(Fawcett et al., 2014). 그러나 대부분의 기술 적 모델링 또는 기전들은 시뮬레이션의 복잡한 이론적 설 명을 넘어서 스포츠 과학자와 임상가에게 실용적인 방식 으로 이 접근을 활용시키는 데는 거의 진전을 보지 못하 고 있다(El-Sayed \& Galea, 2017). 아마도, 네트워크 요소(node)의 역학과 창발 하는 개인특질 간의 연결 고 리가 부족하고 네트워크를 구성하는 변인들의 복잡한 알 고리즘 때문에, 각 조건이 그 네트워크의 역학에 어떠한 영향을 미치는지 탐색하기가 쉽지 않기 때문일 것이다 (Dehmamy et al., 2018). 또한, 스포츠 현상의 다른 척 도와 관점으로 분석될 수 있는 행동(complex behaivor) 을 보기 위한 광범위한 자료의 처리 및 저장 문제가 프로 그램상에서 보다 효율적으로 다루어져야 할 필요가 있다. 그리고, 그 평가 과정이 실제로 거시적 수준의 수행 투입 변수를 관찰하는 동안, 네트워크 자체 구조 안에서 자세 한 통찰력을 동시에 얻기 위한 미시적 수준의 관찰도 다 루어져야 할 것이다(Guardiola et al., 2002).

목적과 가치: 이에 본 연구는 앞서 언급한 필수 개념 및 제안을 바탕으로 스포츠 현장에 적용되고 있는 네트워 크-개인 기반 구조(random structure)의 특성을 소개하 고 잠재적인 위험에 대한 보호 모형을 구축함으로써 체계 역학의 현장 적용 가능성을 시사하는 데 목적을 두고 있 다. 스포츠 현장에서 실패 및 부상과 같은 위험을 예방하 는 데 필요한 잠재요소에 대한 보호를 발견적으로 평가하 고 편향을 일으키는 진화적 원인의 기전을 모형화하고자 한 것이다. 구체적으로 (i) 개인-네트워크에서 양적 측정 을 할 수 있는 단순한 계산 방법을 구축하여 어떻게 보호 잠재성(protection potential)이 위기 잠재성(failure potential)에 영향을 미치는지 거시적 수준은 물론 미시 적 수준에서도 탐색할 수 있게 하였다. (ii) 명확하게 진 술할 수 있는 서로 다른 확률의 가치와 특정 사건으로 인 해 유발된 문제가 그 체계의 기능에 얼마나 심각한 충격 을 줄 수 있는지, 그리고 이러한 위험에 대한 보호 잠재성 이 어떻게 일어날 수 있는지 검사할 수 있도록 하였다. (iii) 위험과 같은 잠재요소를 보다 정확하게 평가하고 이 를 줄이는 방법을 찾기 위해 개인 네트워크 체계에서 실 패의 확산을 다양한 관점으로 관찰할 수 있게 했을 뿐만 아니라, 어떻게 그 위험의 확산에 대한 보호를 일으키는 지 진화론적으로 이해할 수 있게 하였다. 또한, (iv) 이러 
한 특성을 부각시키기 위해 모형의 기전을 단계적으로 구 분하였으며, 그 알고리즘을 제공하였다. 나아가서 (v) 실 질적인 체계적 잠재성에 대한 규칙과 과정을 역학적으로 적용함으로써 스포츠 과학 연구에 필요한 통찰과 잠재적 인 모형을 스스로 구축해 보는데 유용한 안내를 하였다 (Lewis, 2015). 이는 복잡한 스포츠 현상에서 발생하는 개별 과정은 물론, 그 기전을 여러 수준에서 분석할 수 있 도록 도울 것으로 사료 된다.

\section{연구방법}

\section{Model (Mathematical representation)}

개인-네트워크에서 일어나는 잠재적 영향에 관한 기전 을 다음과 같이 구현하였다. 먼저, 기본적인 데이터 구조를 구성하는 네트워크에 있어, 각 요소(nodes)는 무작위 (random)하게 연결(connectivity)하지만 연결의 방향성 은 없다(undirected). 이는 스포츠(or 움직임)는 주요한 (중추신경) 체계의 연합으로써, 체계의 다른 국면(근·신경, 하위 피질 및 하위 척수)으로 실현되는 상호연접의 문제 (Purves et al., 2001)라는 사전 연구의 고찰을 반영한 것 이다. 다음으로 운동기능 또는 스포츠의 네트워크화한 요 소(individuals)의 잠재성을 전제하기 위해 자기조직적인 비선형구조(self-organization, non-linear dynamics)로 서 고전적 매개변수(failure $\approx$ Infected for SIR model, Bjørnstad et al., 2002; Debt for financial model, Colander, et al., 2009)를 사용하였다. 이는 움직임 또는 스포츠의 구조적 특성으로서 주요한 위험의 영향력은 일 반적인 실패 속성(failure potential)의 네트워크 구조를 따라 추정하할 수 있다는 것을 고려한 것이다. 마지막으로 보수, 실패, 전략(payoff, failure, and strategy; Sigmund \& Nowak, 1999) 역학을 위한 진화적(비진화 적) 매개변수들을 포함함으로써 잠재적인 위험에 대한 보 호 기전을 적용하였는데, 이는 생물체 (biological system) 의 움직임 또는 스포츠 현장(sports industry)의 구조에서 창발하는 역동성의 포괄적인 이해를 기반으로 하고 있다 (Turvey et al., 2008).

스포츠 네트워크에서 잠재적 위험 : 다양한 움직임을 일으키는 근·신경 연결과 같은 기능적 구조(Haken,
2012) 또는 복합적인 스포츠 체계에세 긴밀하게 상호작 용(Rosen, 1987)하는 속성으로서 개인(agents or individuals)은 정점 (node $=$ vertice)이고 연결 (link)은 선(line)으로 이어진 두 요소의 집합(edge)이다.

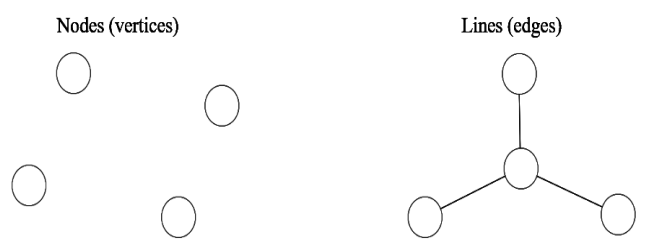

Fig. 1.1. Schematic representation of the nodes and lines.

위 〈Figure 1.1〉에서 정점 사이 선으로 그려진 두 요소 $\left(v_{i}, v_{j}\right)$ 의 집합 $\left[E_{i j}=E\left(v_{i}, v_{j}\right)\right]$ 은 기능적 운동 단위 내 근·신경 또는 스포츠 조직 내 개인 간 연결을 의미하는 것으로 인접 (adjacent)으로 일컬어지기도 한다. Vertices 는 본 모델의 적용에서 어떤 양의 데이터도 저장할 수 있 으며 edge는 그 연결의 강도 $\left[E_{i j} \in\left(0, E_{\max }\right)\right]$ 를 포함할 수 있다.

본 모델의 기본적 구조로서 또 다른 속성은 다른 효과 기를 포함하는 상대성(relativity)이나 환경에서의 안정 성 (stability), 수많은 변수 간의 결합(coupling) 등과 같 은 움직임 또는 스포츠 현상의 비선형적 기본 요소 (Bohm, 1969)로서 연결성 (connectivity)이다.
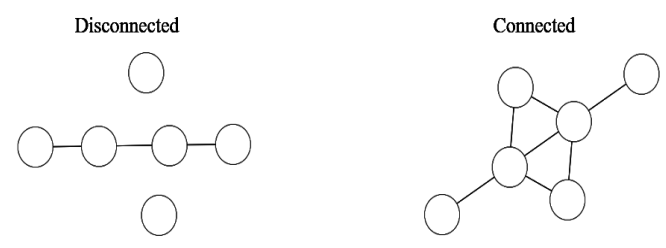

Fig. 1.2. Schematic representation of the connectivity.

비연결성의 네트워크는 일부 개인이 다른 개인과 연결 되어 있지 않아(Figure 1.2 왼쪽) 어느 한 node가 꺼져 있거나, 특정 nodes끼리만 연결을 하고 있을 수 있다. 연 결 네트워크는 이러한 비연결 정점이 없는 상태(Figure 1.2 오른쪽)로서 전체적인 연결을 설명하기 위해 주로 행 렬 (matrix)을 사용한다.

일반적으로 개인 $($ node $=\mathrm{n})$ 과 이들의 연결 $($ connection $=\mathrm{p})$ 로 이루어진 그래프의 정보는 두 정점 간 연결의 방향이 라는 또 다른 속성을 갖는다. 본 모형에서는 움직임 및 스 
포츠 네트워크 특성에 입각하여-연결하고 있는 신경 또 는 개인이 서로 알고 있거나 사전 시행단계에서 접촉 (i.e., tema sports; Clemente et al., 2016)이 있었다 면 연결의 방향은 의미가 없으므로-정점 간 연결의 방향 성이 없는(undirected network) 구조를 적용하였다. 따 라서 모형의 기본적 네트워크 구조는 방향성이 없고 매번 정점 간 연결이 무작위로 이루어지는 속성으로 단순히 4 개의 정점에 가능한 연결을 예로 들면 아래와 같이 표현 될 수 있다.
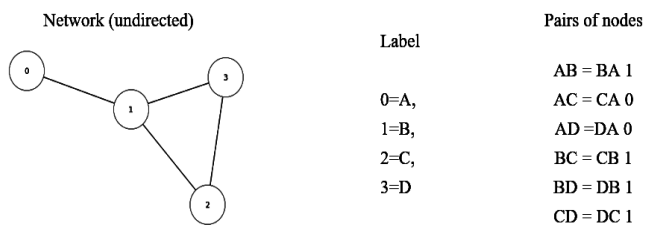

Fig. 1.3. Schematic representation of the structure.

그래프의 두 정점 $(=$ vertices $)$ 을 연결한 간선의 여부 를 2 차원 배열의 행렬(matrix)로 설명하면, 열(rows)과 행 (columns)은 정점에 의해 표현될 수 있기에 위의 예에 서 $1,2,3,4$ 의 정점을 갖게 된다. 이러한 표식은 실제로 인접한 행렬 $(\mathrm{A}=$ adjacent matrix)을 명명하기 위해 부 여한 것으로서 열 $(\mathrm{row}=\mathrm{m})$ 과 행 $($ column $=\mathrm{n})$ 의 여부 (entry)는 1(connection) 또는 0 (no-connection) 중 하나인데, 열과 행 간 연결이 형성되면 1 , 그렇지 않으면 0이 된다.

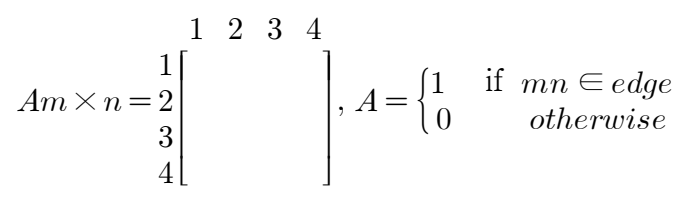

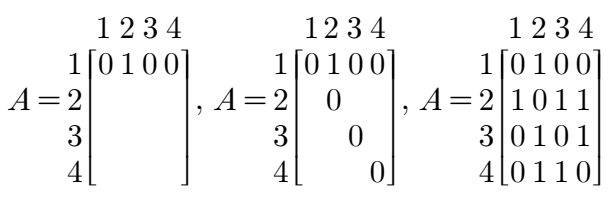

위의 행렬 $(A m \times n)$ 에서 대각선의 요소 즉 그래프의 개인은 스스로 연결 (loop)하지 않기 때문에 항상 0 이다.
행렬에서 열과 행은 정점들을 나타내기에 행렬의 합은 관 계된 정점들의 차수(degree)가 되는데, 예를 들어 정점 이 2 이웃이 3 인 행렬은 아래와 같다.

$$
A=2\left[\begin{array}{llll}
1 & 2 & 3 & 4 \\
1 & 1 & 0 & 0 \\
1 & 0 & 1 & 1 \\
0 & 1 & 0 & 1 \\
0 & 1 & 1 & 0
\end{array}\right], \operatorname{deg}\left(v_{2 m}\right)=3, \operatorname{deg}\left(v_{2 n}\right)=3
$$

행렬 $(A)$ 에서 두 번째 열을 보면 차수가(degree) 3 이라는 것을 알 수 있듯이 인접 행렬은 그래프의 모든 정 보를 포함한다. 시뮬레이션할 때마다 행렬 또는 네트워 크는 다른 모양의 그래프를 보여주겠지만, 아무리 많은 시뮬레이션을 할지라도 생성되는 정점과 연결의 차수 관 계는 아래 공식과 같이 추정될 수 있다.

$\sum_{v=V(G)} \operatorname{deg}(v)=\operatorname{deg}\left(v_{1}\right)+\ldots+\operatorname{deg}\left(v_{n}\right)=2|E(G)|$

공식에서 짐작 할 수 있는 것과 같이 연결의 수는 항상 그 차수의 합의 2 배 $[2|E(G)|=$ i.e., $\mathrm{E}=4=\mathrm{deg}=8]$ 로 나타난 다. 모든 그래프에서, 연결의 수 $[2|E(G)|]$ 는 곧 행렬 요소 들의 합 또는 정점의 차수 합 $\left[\operatorname{deg}\left(v_{1}\right)+\ldots+\operatorname{deg}\left(v_{n}\right)\right]$ 이 되는 것이다. 따라서 행렬 $A$ 의 결과는 $G(n, p)$ 에 의 해 결정되며 $[A=G(n, p)]$, 모든 정점은 랜덤하게 다른 정점에 노출되어 임의의 연결을 생성 할 수 있다. 본 모델 에서는 이러한 연결 확률 $[p \in(0,1)]$ 에 의해 영향을 받은 정점들을 바탕으로 네트워크의 연결 분포가 어느 정도 (probability of degree)인지를 추정하였다.

다음, 단순하게 $p_{-} j$ 로 표현될 수 있는 초기 영향을 받 은 정점 $(1 \leq \mathrm{j} \leq \mathrm{N})$ 들을 기반으로 근·신경 또는 스포츠 체 계의 실패 확률 $[p \in(0,1)]$ 에 따른 잠재적 위험의 전파 과정을 관찰하기 위해 벡터(vector)와 배열 (array)을 사 용하였다. 움직임을 위한 기능적 운동 단위 또는 스포츠 현장에서 모든 개인 $(=$ 요소 $)$ 은 실패 $(=$ 문제 $)$ 또는 실패 가 없는 두 상태 중 하나가 되지만 초기에는 실패가 없이 시작하며, 이러한 실패 역학의 적용으로 확장된 행렬은 아래와 같다. 


$$
\begin{aligned}
& A=\left[\begin{array}{cccc}
a_{11} & a_{12} & \cdots & a_{1 n} \\
a_{21} & a_{22} & \cdots & a_{2 n} \\
\cdots & \cdots & \cdots & \cdots \\
a_{m 1} & a_{m 2} & \cdots & a_{m n}
\end{array}\right]\left[\begin{array}{c}
\vec{a}_{1} \\
\vec{a}_{2} \\
\cdots \\
\vec{a}_{n}
\end{array}\right]
\end{aligned}
$$

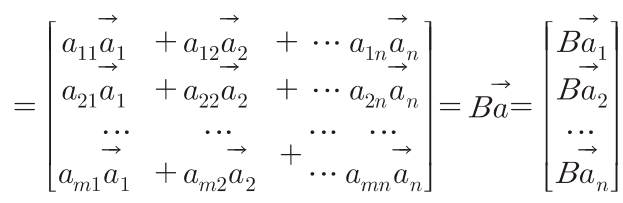

i.e., States Matrix

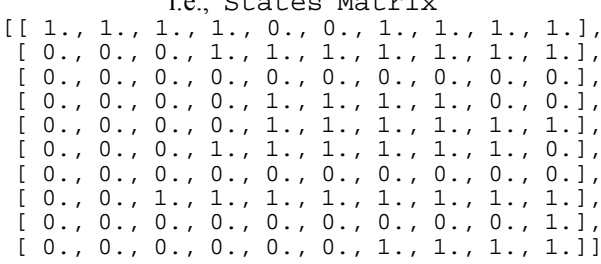

여기서 주목할 것은 행렬이 $A$ 에서 확장되어 $\overrightarrow{B a}$ 가 되 는데 이는 여전히 1 과 0 으로 표현되지만 1 은 실패이고 0 은 실패가 없는 상태 $(1=$ failure, $0=$ absence of failure)를 시계열 상에서 나타내고 있다는 것이다 (States Matrix).

잠재적 위험에 대한 보호 기전: 위의 기본적 구조와 전제를 바탕으로 잠재적 위험의 확산과 이에 대한 보호 역학의 기전을 적용하였다. 먼저, 보수(payoff), 실패 (failure), 전략(strategy)으로 정의한 역학을 모형에 서 하위 그룹으로 나누어 그 결과들이 각각 처리될 수 있 도록 하였는데 이는 계산 및 저장 과정의 시간과 복잡성 을 줄이기 위함이다. 이 방법은 사전에 계산된 변수들 뿐 아니라 새롭게 추가되거나 계산된 변수들을 포함하기 도 하는데 각 부분을 구현하기 위한 절차는 아래와 같다.

$$
\begin{aligned}
\mathrm{a} & \rightarrow \text { store in the table } \\
\mathrm{b} & \rightarrow \text { store in the table } \\
\mathrm{a}+\mathrm{b}=\mathrm{c} & \rightarrow \text { lookup a, } \mathrm{b} \rightarrow \text { compute } \mathrm{c} \\
\mathrm{d} & \rightarrow \text { stored in the table } \\
\mathrm{a}+\mathrm{d}=\mathrm{e} & \rightarrow \text { lookup a, } \mathrm{d} \rightarrow \text { compute } \mathrm{e}
\end{aligned}
$$

위에 제시된 예시와 같이 새로운 변수들을 계산하기 위 해 테이블에서 이미 축적된 값을 일시적으로 저장 및 기 억(memorization)하고 있도록 하는 프로그래밍 기법을 적용하였고, 본 모형에서 중요하게 다루어지고 있는 보 수, 실패, 전략 역학은 각각 아래와 같이 구체화 되었다. 보수(payoff dynamics): 무작위한 네트워크라는 특 성으로 구조화된 기능적 운동 단위 및 스포츠현장 내 각 정점을 반영하는 개인은 아래 제시되는 역학(dynamics) 적 작용에의해 자본 (capital $\approx$ fitness or rationality)과 전략(strategy)으로 특징 지워진다. 스포츠 현장에서 흔 히 나타나는 현상(i.e., professional sports; Rosen \& Sanderson, 2001)과 같이 개인은 시계열상의 각 단계 에서 자신의 운동기능 또는 자본 $(c)$ 에 추가되는 일정양 의 보수(1)를 받고, 그 자본은 각각 자신을 위한 보호 $\left(f_{p}\right)$ 와 유지 $\left(f_{m}\right)$ 를 위해 소비된 자본으로 매 단계마다 갱신된다.

$$
\begin{aligned}
& \text { updated }(c)=1+\left(1-f_{m}-f_{p}\right) c \\
& f_{p}=\vec{v}_{i}=\left[\begin{array}{l}
\vec{v}_{i 1} \\
\vec{v}_{i 2} \\
\ldots \\
\vec{v}_{i n}
\end{array}\right], f_{m}=\vec{v}_{i i}\left[\begin{array}{l}
\vec{v}_{i i 1} \\
\vec{v}_{i i 2} \\
\ldots \\
\overrightarrow{v_{i i n}}
\end{array}\right], \vec{v}_{i i}+(-) \vec{v}_{i}=\left[\begin{array}{l}
\vec{v}_{i i 1}+\left(-\vec{v}_{i 1}\right) \\
\vec{v}_{i i 2}+\left(-\vec{v}_{i 2}\right) \\
\cdots \\
\vec{v}_{i i n}+\left(-\vec{v}_{i n}\right)
\end{array}\right] \\
&=\left[\begin{array}{l}
\vec{v}_{i i i 1} \\
\vec{v}_{i i i 2} \\
\cdots \\
\vec{v}_{i i i n}
\end{array}\right], c\left[\begin{array}{l}
\vec{v}_{i i i 1} \\
\vec{v}_{i i i 2} \\
\cdots \\
\vec{v}_{i i i n}
\end{array}\right]=\left[\begin{array}{l}
c \vec{v}_{i i i 1} \\
\vec{v}_{i i i 2} \\
\ldots \\
\vec{v}_{i i i n}
\end{array}\right]=\left[\begin{array}{l}
\vec{v}_{1} \\
\vec{v}_{2} \\
\cdots \\
\vec{v}_{n}
\end{array}\right]
\end{aligned}
$$

앞서 적용된 네트워크의 기본속성 $(A)$ 이 아래와 같은 행렬 $(B)$ 로 표현된다는 전제에서

$A\left[\begin{array}{cccc}a_{11} & a_{12} & \cdots & a_{1 n} \\ a_{21} & a_{22} & \cdots & a_{2 n} \\ \cdots & \cdots & \cdots & \cdots \\ a_{m 1} & a_{m 2} & \cdots & a_{m n}\end{array}\right]+k A\left[\begin{array}{cccc}k a_{11} & k a_{12} & \cdots & k a_{1 n} \\ k a_{21} & k a_{22} & \cdots & k a_{2 n} \\ \cdots & \cdots & \cdots & \cdots \\ k a_{m 1} & k a_{m 2} & \cdots & k a_{m n}\end{array}\right]=B, \quad k \in[0,1]$

보수 역학이 적용된 결과는

$$
\begin{aligned}
& B=\left[\begin{array}{cccc}
b_{11} & b_{12} & \cdots & b_{1 n} \\
b_{21} & b_{22} & \cdots & b_{2 n} \\
\cdots & \cdots & \cdots & \cdots \\
b_{m 1} & b_{m 2} & \cdots & b_{m n}
\end{array}\right]\left[\begin{array}{c}
\vec{v}_{1} \\
\vec{v}_{2} \\
\cdots \\
\vec{v}_{n}
\end{array}\right] \\
& =\left[\begin{array}{cccc}
b_{11} \vec{v}_{1} & +b_{12} \vec{v}_{2} & +\cdots & b_{1 n} \vec{v}_{n} \\
b_{21} \vec{v}_{1} & +b_{22} \vec{v}_{2} & +\cdots & b_{2 n} \vec{v}_{n} \\
\cdots & \cdots & \cdots & \cdots \\
b_{m 1} \vec{v}_{1} & +b_{m 2} \vec{v}_{2} & +\cdots & b_{m n} \vec{v}_{n}
\end{array}\right]=B \overrightarrow{v v}=\left[\begin{array}{c}
\overrightarrow{B v_{1}} \\
\overrightarrow{B v_{2}} \\
\cdots \\
\overrightarrow{B v_{n}}
\end{array}\right]
\end{aligned}
$$

단순히 행렬 $\overrightarrow{B v}$ 가 된다 $(\vec{v}=$ payoff_dynamics $)$. 
실패(failure dynamics): 실패 잠재성은 각 단계의 개인에서 시작될 수 있는 확률과 $\left[p_{n} \in(0,1)\right]$, 네트워크 화한 그 조직 구성요소의 연결을 따라 전파되는 확률 $\left[p_{l}\right.$ $\in(0,1)]$ 에서 비롯된다. 이 잠재성은 각 개인의 보호를 위한 투자에 따라 실패 확률 $\left(1-p_{p}\right)$ 로 전환되며, 이는 그 단계에서만 지속하는 개인 자본 손실의 원인이 된다.

$p_{p}=p_{p, \max } /\left(1+c_{p, 1 / 2} /\left(f_{p} c\right)\right)$

여기서 보호 $\left(p_{p}\right)$ 기전은 함수(saturation function)로 서, $p_{p, \max }$ 는 보호(maximum)를 의미하고 $c_{p, 1 / 2}$ 는 참 조 점을 반영하며, $f_{p} c$ 는 각 개인이 시계열상의 단계마다 갱신된 자신의 자본을 포함하는 진화적 보호 수준을 반영 한다. 물론 공식 (3)을 통해 짐작 할 수 있듯이 각 부분 $\left(p_{p, \max }, c_{p, 1 / 2}, f_{p} c\right)$ 이 어떠한 상태에 있는가에 따라 다양한 결과 $\left(p_{p}\right)$ 과 초래될 수 있지만, 본 모형에서는 대 부분의 스포츠 체계가 그러하듯이 거시적 수준의 보호장 치 $\left(=p_{p, \max }, c_{p, 1 / 2}\right)$ 는 물론 미시적 수준의 개인 상호작 용 $\left(f_{p} c\right)$ 으로 인한 결과 $\left(p_{p}\right)$ 에도 초점을 맞추었고,

$p_{p}=\vec{u}_{i}=\left[\begin{array}{l}\vec{u}_{i 1} \\ \vec{u}_{i 2} \\ \ldots \\ \vec{w}_{i n}\end{array}\right], \quad f_{p}=\vec{v}_{i}\left[\begin{array}{l}\vec{v}_{i 1} \\ \vec{v}_{i 2} \\ \ldots \\ \vec{v}_{i n}\end{array}\right], \quad f_{p} c=c\left[\begin{array}{c}c \vec{v}_{i 1} \\ \overrightarrow{\vec{v}}_{i 2} \\ \ldots \\ \overrightarrow{\vec{v}_{i n}}\end{array}\right]$

이러한 실패 역학이 적용된 결과는 아래와 같다.

$$
\begin{aligned}
B & =\left[\begin{array}{cccc}
b_{11} & b_{12} & \cdots & b_{1 n} \\
b_{21} & b_{22} & \cdots & b_{2 n} \\
\cdots & \cdots & \cdots & \cdots \\
b_{m 1} & b_{m 2} & \cdots & b_{m n}
\end{array}\right]\left[\begin{array}{l}
\vec{u}_{1} \\
\vec{u}_{2} \\
\cdots \\
\overrightarrow{u_{n}}
\end{array}\right] \\
& =\left[\begin{array}{cccc}
b_{11} \vec{u}_{1} & +b_{12} \vec{u}_{2} & +\cdots & b_{1 n} \vec{u}_{n} \\
b_{21} \vec{u}_{1} & +b_{22} \vec{u}_{2} & +\cdots & b_{2 n} \vec{u}_{n} \\
\cdots & \cdots & \cdots & \cdots \\
b_{m 1} \vec{u}_{1} & +b_{m 2} \vec{u}_{2} & +\cdots & b_{m n} \vec{u}_{n}
\end{array}\right]=B \vec{u}=\left[\begin{array}{c}
B \vec{u}_{1} \\
\overrightarrow{B u_{2}} \\
\cdots \\
\overrightarrow{\vec{u}_{n}}
\end{array}\right]
\end{aligned}
$$

여기서 벡터 $(\vec{u})$ 요소는 행렬 $B$ 와 같으므로 $(\vec{u}=$ failure_dynamics) 역학적 결과는 다시 $B \vec{B}$ 가 된다. 앞 서 언급한 바와 같이 모형의 기본 속성으로서 적용된 무
작위 네트워크(random-graph)를 벡터 $(\vec{u})$ 화하기 위해 1 차원 배열(array)을 적용하였는데 이를 통해 일일이 반 복(loop)되는 매 계산과정을 단순화하였다.

전략(strategy dynamics): 본 모형을 위해 가상으로 구조화한 근·신경 및 스포츠의 체계(random structure)의 모든 요소이자 개인은 $0.1-f_{m}$ 간격에서만(truncation) 경험·발견적 문제해결(heuristics)을 통해 각자의 보호 수준 $\left(f_{p}\right)$ 을 선택한다.

$f_{p}=f_{p 0}+f_{p 1} C$

특히, 대부분의 스포츠(경기 또는 산업)에서 우리가 취할 수 있는 정보는 제한적(Newell \& Ranganathan, 2010)일 뿐만 아니라 시간상 충분히 심사숙고하여 판단 할 수 있도록 허용하지 않는다(Gréhaigne et al., 2001). 따라서, 신속하게 의사결정 하는 상황을 전제로(휴리스 틱) 각자가 선택한 보호 수준은 단순히

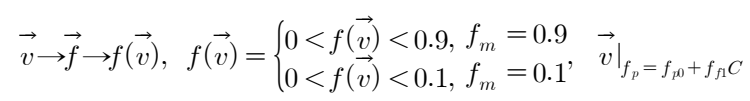

되고, 이 과정에서 각 개인이 선택할 수 있는 전략을 두 가지로만 정의 $\left(f_{p 0}, f_{p 1} C\right)$ 하였으며, 두 전략의 값을 초 기화하기 위해 두 개의 배열(array)이 추가되었다 $\left\lceil\left(f_{p 0}=\vec{W}_{i}\right),\left(f_{p 1} C=C \vec{W}_{i}\right)\right]$.

$f_{p 0}=\vec{w}=\left[\begin{array}{c}\vec{w}_{1} \\ \vec{w}_{2} \\ \ldots \\ \vec{w}_{n}\end{array}\right], \quad f_{p 1} C=C \vec{w}\left[\begin{array}{c}\overrightarrow{C \vec{w}_{1}} \\ C \vec{w}_{2} \\ \ldots \\ \overrightarrow{C w_{n}}\end{array}\right], \quad C \in[0,1]$

$\vec{W}_{i 1}$ 는 하나의 전략 $\left(f_{p 0}\right)$ 으로 벡터화된 것이고, $\vec{W}_{i i}$ 는 적용된 기본 네트워크 중심성 속성〔Erdös-Renyi graph $(C)$ ]이 포함된 또 다른 전략 $\left(f_{p 1}\right)$ 의 벡터화이다. 


$$
\begin{aligned}
f_{p 0}=\vec{w}_{i} & =\left[\begin{array}{l}
\vec{w}_{i 1} \\
\vec{w}_{i 2} \\
\ldots \\
\vec{w}_{i n}
\end{array}\right], f_{p 1} C=C \vec{w}_{i}\left[\begin{array}{c}
C \vec{w}_{i 1} \\
\overrightarrow{C w}_{i 2} \\
\ldots \\
C \vec{w}_{i n}
\end{array}\right], \vec{w}_{i}+C \vec{w}_{i} \\
& =\left[\begin{array}{l}
\vec{w}_{i 1}+C \vec{w}_{i 1} \\
\vec{w}_{i 2}+C \vec{w}_{i 2} \\
\cdots \\
\vec{w}_{i n}+C \vec{w}_{i n}
\end{array}\right]=f_{p}=\left[\begin{array}{c}
\vec{v}_{i 1} \\
\vec{v}_{i 2} \\
\cdots \\
\vec{v}_{i n}
\end{array}\right]
\end{aligned}
$$

여기서 $C$ 는 0 1 사이에서 표준화된 개인(node)의 측정된 중심성 $(\lambda x)$ 이다. 그리고, 위와 같이 팀 또는 산 업 내에서 각 개인이 휴리스틱을 통해 선택하게 되는 전 략 $\left(f_{p 0}\right.$ 와 $\left.f_{p 1} C\right)$ 의 사회적 학습 기전을 적용하기 위해 다 음과 같은 모방과 전략적 탐색을 포함하였다.

시계열 상의 각 단계에서 개인은 인위적으로 설정된 확률 $\left[p_{r} \in(0,1)\right]$ 에 따라 자신의 역할 모델로써 다른 개인을 무작위로 선택하고 그 개인의 전략 값을 아래 공 식 $\left[p_{i}\right]$ 에 따라 모방한다.

$p_{i}=\left[1+e^{-w \Delta \pi}\right]^{-1}, \pi_{r}-\pi_{f}=\left.\Delta \pi\right|_{\pi_{r}=\text { rolemodel }}$

여기서 $w$ 는 개인이 다른 개인을 선택하게 되는 선택 의 강도이고 $\triangle \pi$ 는 개인이 선택한 다른 개인 $\left(\pi_{r}=\right.$ role model $)$ 의 자본과 자신 $\left(\pi_{f}=\right.$ focal model $)$ 의 자본 간의 차이를 의미한다. 공식에 따르면, 무작위하게 선택한 다른 개인 $\left(\pi_{r}\right)$ 의 자본이 자신 $\left(\pi_{f}\right)$ 의 자본보다 클수록 그 개인을 모방할 확률이 높아지지만, 그렇지 않다면 모 방할 확률은 낮아[i.e., $0.99=1 /\left(1+e^{-10(0.9-0.1)}\right)$, $\left.0.001=1 /\left(1+e^{-10(0.1-0.9)}\right)\right]$ 진다.

마지막으로 각 단계에서 개인은 인위적으로 설정한 확 률 $\left[p_{e} \in(0,1)\right]$ 에 의해 두 전략 값 중 하나를 무작위로 선택하고 평균 $(0)$ 과 표준편차 $(\sigma \in(0,1))$ 의 표준적 증 분(normally distributed increment)에 의해 자신의 전 략 값을 전환한다.

$f\left(x \mid \mu, \sigma^{2}\right)=\frac{1}{\sqrt{2 \pi \sigma^{2}}} \exp ^{-\frac{(x-\mu)^{2}}{2 \sigma^{2}}}$

$x=$ individual capital, $\mu \in R=$ mean(location), $\sigma^{2}>0=$ variance(squared scale)

\section{연구결과}

이러한 기전을 바탕으로 잠재적 위험(failure potential) 에 대한 보호 역학(protection potential) 모형의 결과는 다음과 같이 두 부분으로 구성하였다. 첫 번째 부분은 사 전 연구의 고찰을 통해 조작적으로 정의한 근·신경 및 스 포츠 체계의 무작위한 네트워크 특성과 이 구조에서 발생 할 수 있는 위험 확산의 기본적 양상을 기술하였다. 두 번 째 부분에서는 적용된 역학적 개념들로부터 가상의 스포 츠 현상(작게는 기능적 운동 단위로서 움직임에서 크게 는 전체산업까지) 내 개인의 휴리스틱과 모방 및 탐색을 통해 일어나는 실패 확률에 대한 실제적 보호를 추정하였 으며, 그 특징적인 관찰을 기술하였다.

\section{Part1: 기본 구조(랜덤 네트워크에서)}

시뮬레이션에서 개인은 그래프를 구성하는 기본적인 요소로서 정점 (vertices)이고 선(line)은 두 정점을 연결 하여 집합(edge)을 이루었다. 이는 일반적인 그래프의 정보로 두 매개변수 $(n, p)$ 에 의해 조절되는데 여기서 $n$ 은 특정 팀의 구성원(개인) 수를 반영하고, $p$ 는 그들의 연결 정도를 의미하였다(Figure 2.1).

〈Figure 2.1〉은 전형적으로 표현되는 그래프 이론을 따르고 있다. 간단한 도수 분포(degree distribution) 방 법을 통해 스포츠에서 개인(neuron or athelate) 즉 정 점의 고차계 (higher-degree)가 높을수록 다른 개인과 연 결될 기회가 더 높다는 사실을 보여주고 있는 것이다.

조금 더 구체적으로 위의 인위적으로 고안된 네트워크 $\lceil G(n, p), n=10$ and $p=0.9$ ]를 예로 가능한 연결의 수는 $n(n-1) / 2=10^{*} 9 / 2=45$ 이고 개인 차수 (node degree)의 평균은 $n(n-1)=0.9 * 9=8.1$ 이 된다. 모든 개인이 가지는 차수의 확률을 수량화하면 $0 \leq d \leq(n-1)$ 이 되는데 여기서 개인의 도수가 0 이 면 누구와도 연결되지 않음을 의미하고, 모든 개인과 연 결되었다면 그 개인이 가지는 도수는 $n-1$ 이 된다. $n$ 개 의 개인으로 이루어진 기능적 운동 단위 또는 팀에서 한 개인이 $d$ 의 차수를 가졌다면 $n-1-d$ 로 표현될 수 있 는데 이는 연결이 있지만 자기 스스로 연결은 없기 때문 이다. 따라서 개인의 연결 확률이 $p$ 이기 때문에, 연결되 지 않는 확률은 $n-p$ 가 되고 단순히 이항분포(binomial distribution)로서 개인이 가지는 도수(degree)의 확률 

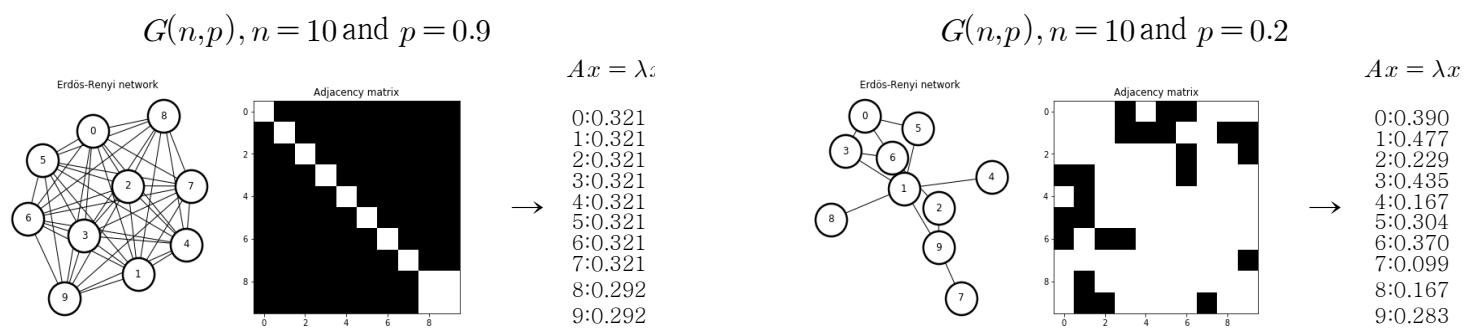

Fig. 2.1. A prototype of the random network with its property. Number of nodes $\mathrm{n}=10$, Connection probability $\mathrm{p}=0.9$ (left set), $\mathrm{p}=0.2$ (right set). At each section, the plots of the left side show the random (Erdös-Rényi) network created. A circle represents each node with an arbitrarily assigned label from 0 to 9 , and each line represents a link. The plots of the middle show their adjacency matrix with its entry in row column (either $1=$ black or $0=$ white) corresponding to its eigenvector centrality (right side).

은 $\mu=p(n-1)$ 로 개인의 도수 평균과도 같게 된다.

이를 바탕으로 각 개인의 차수에 따라 연결된 개인 간 연결의 평균 길이 (path length)와 시간(time)을 추정하 였다. 연결 확률이 낮으면 $[p(d)]$ 연결의 수가 작고, 일부 개인들이 고립될 수 있으며, 연결의 길이와 시간 차이가 크지만 $p(d)$ 가 큰 경우에는 거의 완전한 그래프 (complete graph)가 형성되고 경로의 길이와 시간의 차 이가 짧아졌다. 또한, 어떤 개인이 가장 중요한 역할을 하 는지를 식별하기 위해 중심성 (eigenvector centrality: 개인이 네트워크에서 차지하는 중요성)을 추정하였는데 이는 그 체계에서 각기 다르게 작용할 수 있는 개인의 영 향력을 알아볼 수 있게 하였다.

특히, 이 중심성은 네트워크의 인접행렬 특성 $\lceil A x=\lambda x, \lambda=$ eigenvalue $〕$ 으로 조직 내 특정 개인 에 대한 연결이 높을수록, 중심성이 커지는데 이는 모델 의 기본 특성과 관련하여 이웃 중 어떤 하나(중심성이 높 고 낮고)가 감염되는가에 따라 무엇이 그 네트워크를 통 해 문제를 확산시키는지 관찰하게 하는 지표가 되기도 하 였다.

계단식 실패의 명제: 위의 무작위 네트워크 기본 속 성을 바탕으로, 개인은 실패 또는 실패하지 않은 둘 중의 하나의 상태가 된다. 물론 모든 개인은 실패하지 않은 상 태에서 시작한다. 초기 영향을 받은 것으로 설정된 개인 $(1 \leq \mathrm{j} \leq \mathrm{N})$ 과 실패 확률 $[p \in(0,1)]$ 로서 배열을 사용 (방법 참고)하였는데 이는 간단히 $p_{-} j$ 이다. 실패를 결정 하는 근본적 속성 $\left(s_{i j}\right)$ 은 그 맥락에서 각 개인의 연결로 부터 이루어지는데, 위험의 기본 수준은 네트워크에서 동
시에 일어나는 $i$ 와 $j$ 에 의해 결정된다. 이는 기능적 운동 단위 및 스포츠 현상에서 더 많이 연결된 개인일수록 더 높은 편향이 일어난다는 것을 반영하기에 실패 확률은 얼 마나 많은 다른 개인들과 연결되어 있는지의 척도 $(R / S)$ 에 의해 특징 지워질 수 있었다. 즉, 저마다 상이할 수 있 는 개인적 기본 특성을 상수 $(k)$ 로 간주한다면 스포츠 현 상의 위험은 고육벡터 중심성 $(\lambda x \leftarrow p \in(0,1))$ 에 의해 생겨난 연결의 함수 $(R=k / S)$ 로서 간단히 추정될 수 있 었다. 다시 말해서 조직 내 각 개인이 자신의 기본적 특성 을 모든 과정에서 유지하고 있다 하더라도 그 체계에서 개인을 반영하는 정점의 수를 감소하거나 정점의 연결을 낮춘(Figure 2.2)다면 편향 또는 위험 확산을 낮출 수 있 다는 것이다.

단순한 기전을 바탕으로 한 이러한 시뮬레이션 결과 가 의미하는 바는 높은 차수 $(=$ 연결 $)$ 일수록 계단식 실패 에 빠질 위험이 낮은 차수의 경우보다 높을 수밖에 없고, 이는 전체 체계를 붕괴시킬 수 있는 잠재성을 증가시킬 수밖에 없다는 것이다.

\section{Part 2: 현실적 역동성을 부여한 실패에 대한 보호}

위와 같은 모형의 기본 속성을 바탕으로 실패 위험에 대한 보호 역학을 적용하였다. 각 개인이 보호를 위해 투 자를 할 수 있도록 한 것이다. 여기서 실패 잠재성으로서 체계적 위험은 개인이 보호를 위해 얼마나 투자 하였는가 $\left\lceil p_{p}=p_{p, \max } /\left(1+c_{p, 1 / 2} /\left(f_{p} c\right)\right)\right]$ 에 따라 실패 확률 $\left(1-p_{p}\right)$ 이 되고 이러한 실패는 시계열상 각 단계에서만 지속하였다. 

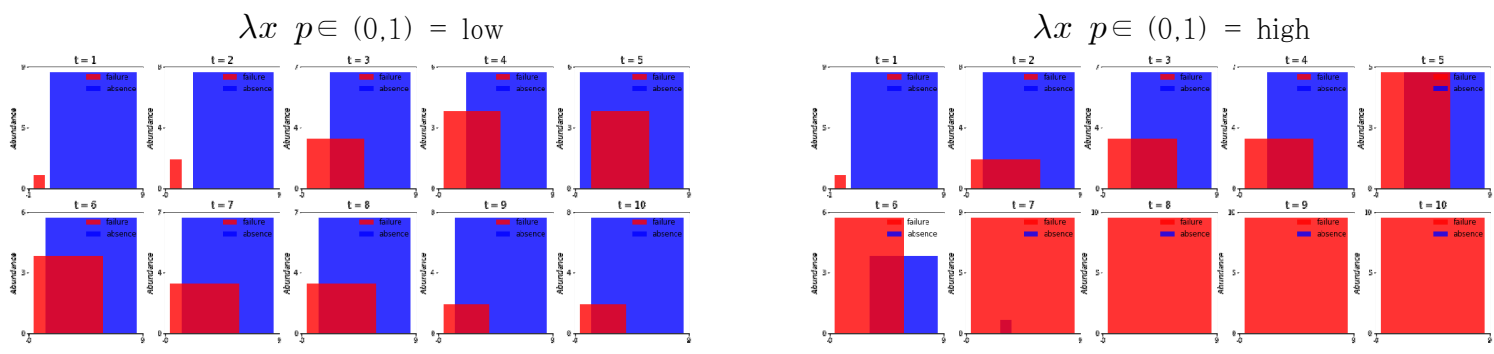

Fig. 2.2. Visualization of the failure propagation with distribution. The plot of the left $(\lambda x=$ low $)$ and right $(\lambda x=$ high $)$ shows the number of failures for time step $(\mathrm{t}=10)$ corresponding proportional area to the values. It shows the more the propagates, the bigger the area has been drawn between the failure (red) and the absence of failure (blue) at each time step.

〈Figure 3〉에서 각 개인은 정점(node)으로 그려지 고, 두 개의 정점을 연결하는 선(lin)은 인접한 개인과 의 연결(edge)을 의미한다. 각 정점의 크기는 차수 (degree)로서 그 정점이 얼마나 많은 연결을 하고 있는 지를 대변하고, 연결선의 굵기는 중심성 (centrality)으 로서 그 정점의 영향력을 나타내고 있다. 움직임의 기능 적 단위 및 스포츠 현장내 위험의 잠재성은 인위적으로 고안된 초기 실패 확률로서 실패 역학을 통해 전파되고,
이에 대한 적절한 보호는 실패의 부재를 위한 잠재성으 로서 모방과 탐색의 전략적 역학을 통해 경험·발견적으 로 진화한다. 그리고 각 각본(Figure 3s Scenario $\mathrm{A} \sim \mathrm{D})$ 의 가능한 확률들은 다음과 같이 추정되었다. 첫 째, 각본 $\mathrm{A}$ 의 시뮬레이션에서 주어진 매개변수들의 값 $\left(p_{p, \max }=1, c_{p, 1 / 2}=1, p_{r}, p_{e}=0.9, C=1\right)$ 을 기반 으로 가능한 보호 확률 $p_{p}=p_{p, \max } /\left(1+c_{p, 1 / 2} /\left(f_{p} c\right)\right)$ $=1 /\left(1+1 /\left(0.9^{*} 1\right)\right.$ 의 값이 $\left(p_{p}=0.473\right)$ 이기 때문에 실

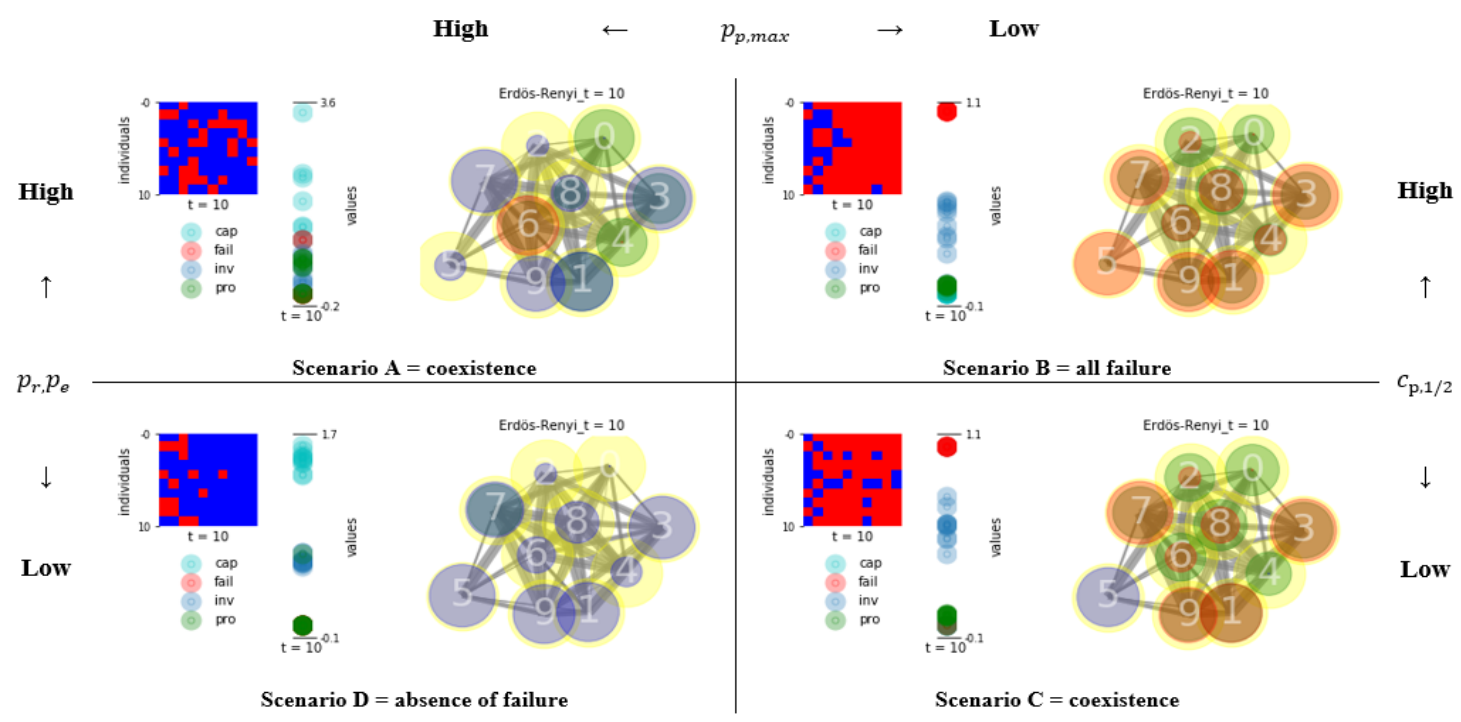

Fig. 3. Protection dynamics against the risk potential. At each section, plots of the left-hand side show the matrix [horizontal axis = time step from 1 to 10 , vertical axis $=$ individuals $(10)$, color of the matrix $=$ failure state between fail (red) and absence of fail (blue)]. The plots of the middle show each individuals' parameter values at the time step [ $\mathrm{t}=10$ : cyan: cap=capital $(\mathrm{c})$, red: fail=failure, blue: inv=investment $\left(f_{p}\right)$, green: pro=protection potential $\left.\left(p_{p}\right)\right]$. The plot on the right-hand side represents individuals' dynamics within a random network; node number $=$ random label of each node, line width $=$ eigenvector centrality, node color $=$ states [failure (red) $\longleftrightarrow$ (gray) absence of failure, green $=$ protection potential, yellow $=$ initial structure of the state without failure and protection]. Initialized parameters of the simulations are: nodes $\mathrm{n}=10$, connection $\mathrm{p}=0.9, f_{m}=0.1, p_{n}=0.1, p_{l}=0.3, \mathrm{t}=10$. 
패 잠재성 $\left(1-p_{p}\right)$ 은 0.527 이 된다. 둘째, 각본 $\mathrm{B}$ 의 시 뮬레이션에서 주어진 매개변수들의 값 $p_{p, \max }=0.1$, $\left(c_{p, 1 / 2}=1, p_{r}, p_{e}=0.9, C=1\right)$ 을 기반으로 가능한 보호 확률 $p_{p}=p_{p, \max } /\left(1+c_{p, 1 / 2} /\left(f_{p} c\right)\right)=0.1 /$ $\left(1+1 /\left(0.9^{*} 1\right)\right.$ 의 값이 $\left(p_{p}=0.047\right)$ 이기 때문에 실패 잠 재성 $\left(1-p_{p}\right)$ 은 0.953 이 된다. 〈Figure 3 〉의 오른쪽 위 그래프에서 볼 수 있듯이, 이 각본은 시간이 지날수록 모 두가 실패하게 되는 결과를 초래하고 있다. 셋째, 각본 C 의 시뮬레이션에서 주어진 매개변수들의 값 $\left(p_{p, \max }=0.1, c_{p, 1 / 2}=0.1, p_{r}, p_{e}=0.1, C=1\right)$ 을 기반으로가능한보호확률 $p_{p}=p_{p, \max } /\left(1+c_{p, 1 / 2} /\left(f_{p} c\right)\right)$ $=0.1 /\left(1+0.1 /\left(0.1^{*} 1\right)\right]$ 의 값이 $\left(p_{p}=0.005\right)$ 이기 때문 에 실패 잠재성 $\left(1-p_{p}\right)$ 은 0.95 가 된다. 마지막으로, 각 본 $\mathrm{D}$ 의 시뮬레이션에서 주어진 매개변수들의 값 $\left(p_{p, \max }=1, c_{p, 1 / 2}=0.1, p_{r}, p_{e}=0.1, C=1\right)$ 을 기 반으로 가능한 보호 확률 $p_{p}=p_{p, \max } /\left(1+c_{p, 1 / 2} /\left(f_{p} c\right)\right)$ $=1 /\left(1+0.1 /\left(0.1^{*} 1\right)\right)$ 의 값이 $\left(p_{p}=0.5\right)$ 이기 때문에 실 패 잠재성 $\left(1-p_{p}\right)$ 은 0.5 가 된다. 〈Figure 3 〉의 왼쪽 아 래 그래프에서 볼 수 있듯이, 이 각본은 시간이 지날수록
모두가 실패하지 않게 되는 결과를 보여주고 있다.

보호 수준(protection level): 위에 제시하고 있는 기본적 각본을 바탕으로 시뮬레이션의 초점을 (운동 기능 또는 팀은 물론 스포츠 종목 또는 산업의 측면으로 확대) 더 많은 시간과 개인들의 진화적 보 호 수준 $\left(f_{p} c\right)$ 으로 발전시켰다. 이는 적용된 함수 $p_{p}=p_{p, \max } /\left(1+c_{p, 1 / 2} /\left(f_{p} c\right)\right)$ 의 맥락에서 보호 수준 의 참조점 $\left(p_{p, \max }, c_{p, 1 / 2}\right)$ 을 상수로 한 시뮬레이션의 결 과는 네트워크 속성 $(\lambda x=\mathrm{C})$ 과 함께 모방 $\left(p_{r}\right)$ 과 탐색 $\left(p_{e}\right)$ 을 통한 휴리스틱 $\left[p_{r}, p_{e}, C \rightarrow\left(f_{p} c\right)\right]$ 에 의해 달라 질 수 있다는 가정을 고려한 것이다. 각 개인의 결정에서 일어난 실패 전파와 그 위험에 대한 보호를 위한 투자는 개인 스스로 이루어낸다는 것을 의미하는 설정이다.

〈Figure 4.1〉은 보호 매개변수 $p_{p, \max }=1, c_{p, 1 / 2}$ $=0.5$ 를 고정하고 근.신경 및 스포츠 체계 특성을 기반으 로 적용한 무작위 네크워크 속성 $(C)$, 모방 $\left(p_{r}\right)$, 탐색 $\left(p_{e}\right)$ 의 확률을 변화시킴에 따라 다르게 관찰된 진화적 결 과를 보여주고 있다. 각본 $\mathrm{A}$ 는 네트워크 개인 간의 연결, 모방, 그리고 탐색이 모두 높게 설정된 조건 $\left[\right.$ for $f_{p} c: p$

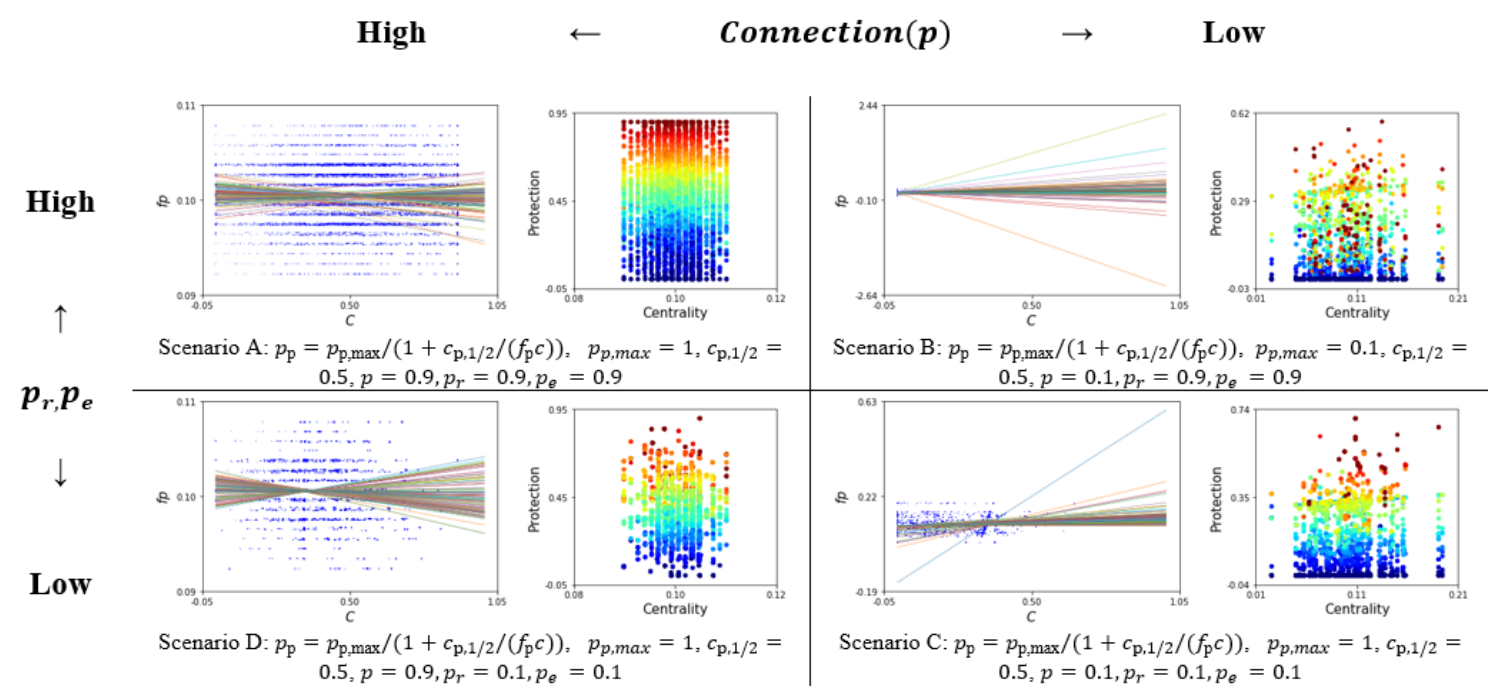

Fig. 4.1. Protection dynamics against the risk potetntial with pattern recognition. At each section, the plot of the left-hand side shows the relation between protection level $\left(f_{p}\right)$ and the eigenvector centrality which is controlled by the initialized random network property $[(G(n, p)) \rightarrow$ Centrality = eigenvector centrality $]$ according to time steps (100). The blue dots represent individuals, and the lines represent regressions at each time steps. The plots of the right-hand side at each section represent that large connection probability caused asymmetric pattern with the correlation between the two parameters. Instead, the small connection probability does not. 
$\left.=0.9, p_{r}=0.9, p_{e}=0.9\right]$ 에서 관찰된 결과이다. 각본 $\mathrm{B}$ 는 네트워크 개인 간 연결이 낮지만 모방과 탐색은 높은 경우[for $f_{p} c: p=0.1, p_{r}=0.1, p_{e}=0.1$ ] 이고, 각본 $\mathrm{C}$ 는 각 개인 간 연결, 모방, 탐색 모두 낮게 설정된 경우 〔for $f_{p} c: p=0.9, p_{r}=0.9, p_{e}=0.9$ 〕이며, 각본 $\mathrm{D}$ 는 네 트워크 개인 간 연결은 높은 반면 모방과 탐색은 낮게 조 건 (for $f_{p} c: p=0.9, p_{r}=0.1, p_{e}=0.1$ )화된 결과를 보 여주고 있다.

네 가지 각본의 시뮬레이션은 시간에 따라 다른 진화 적 양상으로 관찰되었다. 기능적 운동 단위 또는 스포츠 산업의 개인 간 연결이 작은 경우(connection $p=0.1$ ), 약한 상호작용 양식은 중심성 (centrality)의 분포를 증가 시킨 반면, 개인 간 연결이 높은 경우(connection $\mathrm{p}=0.9$ ) 중심성의 분포가 상당히 줄어들었다. 또한, 일단 네트워크 개인 간 연결성이 높은 체제에서 강한 상호작용
은 중심성과 보호 수준의 대칭 $($ symmetric $=$ Scenario A)적 양상을 일으키는 원인이 된 반면, 연결성이 낮은 경 우 그렇지 않은 것 (Scenario C)으로 관찰 되었다. 이러 한 결과는 매개변수로서 고육벡터 중심성 $\lceil\lambda x \leftarrow \mathrm{p} \in$ $(0,1)]$ 이 근·신경 및 스포츠 체계의 규모와 관계하여 잠 재적 위험에 대한 보호 요인에 어떠한 영향을 일으키고 있는지 조금 더 분명한 통찰을 주고 있었다.

전략(strategy): 이어서, 움직임을 포함하여 다양한 스포츠 현상에서 모방과 탐색을 통해 일어나는 대안적인 전략 $\left(f_{p 0}\right.$ 와 $\left.f_{p 1}\right)$ 이 실패 잠재성에 영향을 줄 수 있는지 의 특성을 분석하였다. 근·신경 조직, 스포츠팀 또는 산업 조직 속성의 강한 중심성 $[\lambda x \leftarrow(\mathrm{p}=0.9)]$ 을 바탕으로 높은 보호 $\left(p_{p, \max }\right)$ 환경 및 모방 $\left(p_{r}=0.9\right)$ 이 있지만 각 개인이 모방한 다른 개인의 전략을 다른 전략으로 전환할
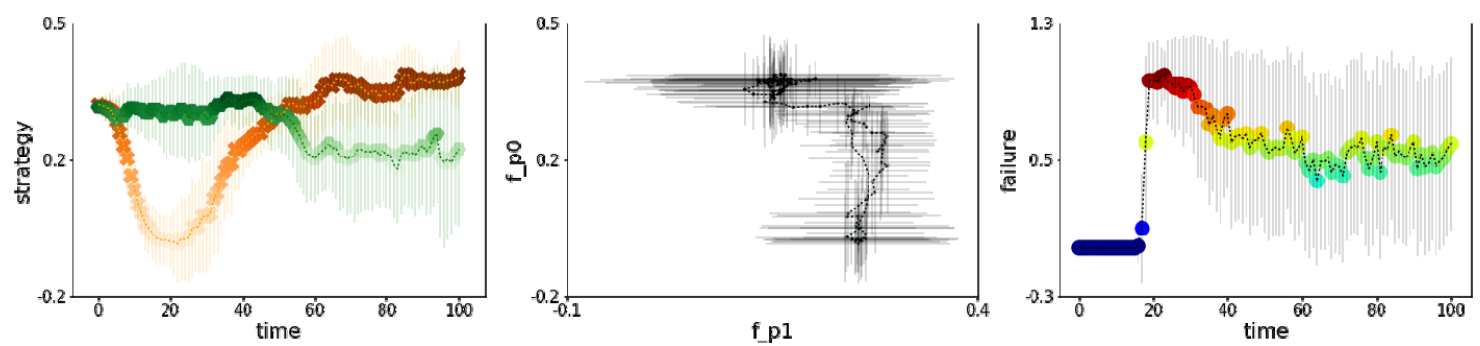

Fig. 4.2. Described protection dynamics against the risk potential with small exploration rate. The plot of the left-hand side shows a trend of the two strategies ( $f_{p 0}=$ red, $f_{p 1}=$ green, dashed vertical lines $=$ variability), corresponding to its evolutionary trajectory (middle side of the plot: dot $=$ averaged value, strength of the dot $=$ time step, dashed horizontal and vertical lines = variability). The plot of the right-hand side represents the failure [vertical axis: node color $=$ strength [failure (red) $\longleftrightarrow$ (blue) absence of failure] and variability (dashed vertical line) at each time step (horizontal axis). Initialized parameters of the simulations are: nodes $\mathrm{n}=100$, connection $\mathrm{p}=0.9$, capital $\mathrm{c}=1, f_{p 0}=0.3, f_{p 1}=0.3, f_{m}=0.1$, , $p_{r}=0.9, p_{e}=0.1, \mu=0.0, \sigma=0.1, p_{p, \max }=1, c_{p, 1 / 2}=0.5, p_{n}=0.001, p_{l}=0.1, \mathrm{t}=100$.
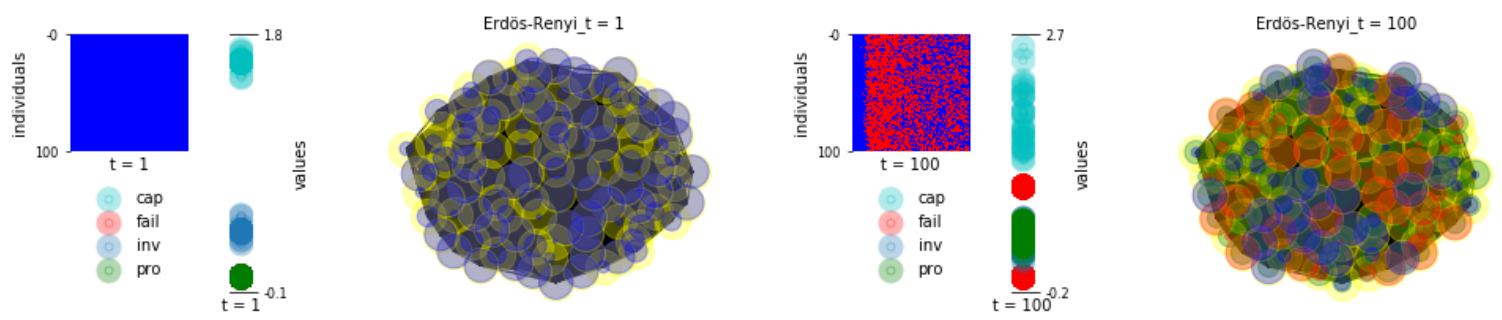

Fig. 4.3. Protection dynamics against risk potential with small exploration rate. At each section, plots of the left-hand side show the matrix [horizontal axis $=$ time step from 1 to 100 , vertical axis $=$ individuals from 0 to 100 , color of the matrix $=$ failure state between fail (red) and absence of fail (blue)]. The plots of the middle show each individuals' parameter values at the time step [ $=100$ : cyan: cap=capital (c), red: fail=failure, blue: inv=investment $\left(f_{p}\right)$, green: pro=protection potential $\left.\left(p_{p}\right)\right]$. The plot on the right-hand side represents the individuals' dynamics with a random network; node color $=$ states [failure (red) $\longleftrightarrow$ (blue) absence of failure, green $=$ protection potential, yellow $=$ initial structure of the state without failure and protection]. 
수 있는 탐색 $\left(p_{e}=0.1\right)$ 을 거의 할 수 없다는 조건의 시뮬 레이션이다. 이는 보호 수준을 결정하는 기전 $\left(f_{p}=f_{p 0}+f_{p 1} C\right)$ 에 따라 탐색 확률은 다른 수준의 보 호 잠재성을 일으킬 수 있으므로, 매개변수 $p_{e}$ 의 값이 작 아지면 보호 수준의 결과가 기대하는 만큼 달성되기 어려 울 수 있다는 가정이다. 다시 말해서, 각 단계에서 인위적 으로 적용된 확률 $\left(\mathrm{random} \% \leq p_{r}, p_{r}=0.9\right.$ )에 따라 그 체계 내 대부분의 개인은 각자의 역할 모델로서 다른 개 인을 선택할 수 있고 자신이 선택한 역할 모델의 전략 값 (strategy values $=$ capital)을 모방할 수 있다 $\left\lceil p_{i}=\left[1+e^{-w \Delta \pi}\right]^{-1}\right]$ 할지라도, 자신이 선택하지 않 은 다른 개인들의 전략을 탐색할 기회가 없어서 자신의 전략 값을 다른 전략 값으로 전환하기가 어렵다는 것이다 (Dunning, 1999).

〈Figure 4.2〉는 네트워크 이론(Graph theory)의 두 드러진 논쟁요소의 측면에서 단순하게 두 가지로 구분되 는 구성원 $(n=100)$ 중 $f_{p 0}$ 를 하나의 전략, $f_{p 1}$ 를 다른 하나의 전략으로 간주하고 시계열 상에서 각 단계(time steps)에 따른 변수들의 평균을 보여주고 있다. 같은 조 직에 포함되어 있다 하더라도 그 체계의 중심성 속성 $(A x \Rightarrow$ eigenvectorcentrality $=C)$ 을 포함하고 있 는 전략 $\left(f_{p 1} C=\right.$ green $)$ 과 이를 포함하지 않고 있는 전략 $\left(f_{p 0}=\mathrm{red}\right)$ 간 다른 행동적 양상이 관찰 되었다(Figure 4.2 왼쪽). 시뮬레이션 결과 개인 간 모방이 활발하게 이 루어질 수 있는 $\left(p_{r}=0.9\right)$ 조건에서 탐색은 두 전략 간 다 르게 나타나는 행동적 추세의 원인이 되었으며 그 차이는 시계열 상에서 기하급수적으로 달라졌다. 높은 중심성은 앞선 관찰에서와같이 전체 체계를 붕괴시킬 수 있는 잠재 성을 증가시키기도 하지만 모방과 탐색이라는 진화적 매 개변수의 조합을 달리 한 경우에는 개인의 행동 (=strategy value including capital)을 다르게 하는 또 하나의 잠재성(i.e., protection)으로 작용한 것으로 해 석된다.

개념적으로 낮은 탐색이 시간의 흐름에 따라 매개변수 와 관계한 개인의 다른 행동을 비선형적으로 증가시킨다 는 것을 반영하고 이러한 밀도는 근·신경 및 스포츠 조직 의 기본구조가 다음 단계에서 발생할 수 있는 가능성 (체 계적 위험의 확산)을 제한할 수 있다는 것을 나타내었다. 또한, 〈Figure 4.3〉에서 보여주는 바와 같이 개인의 자본 $(\mathrm{cap}=\mathrm{capital})$ 과 실패 $($ fail=failure $)$ 간 부적 상관관계 (negative correlation)가 관찰되었으며, 이러한 편향은 초기 단계에서 더 급격히 일어나는 것을 확인 할 수도 있 었다. 따라서 중심성 (거시적 수준)과 탐색 (미시적 수준) 의 확률은 움직임 및 스포츠 체계를 새로운 경향으로 이 어질 수 있게 하는 자원을 제공하는 또 다른 중요한 요인 이 될 수 있음을 확인할 수 있었다(Cassidy et al., 2008).

\section{논 의}

우리의 심리·행동적 다양성은 체계의 자발적 또는 외 부적 구조 및 기능에 따라 깨진다(Collins \& Stewart, 1993). 근·신경 단위로서 사지의 움직임 체계뿐만 아니 라 사람 또는 조직 간의 체계 등 다양한 조건에서 스포츠 에 내재되어 있는 이러한 현상은 보다 객관적으로 이해되 어야 할 필요가 있을 것이다. 어떤 외부적 또는 내부적 요 인이 우리가 당면한 복잡함(complexity)에서 중요하게 다루어져야 하는지를 경험적으로 확대 (Park, 2018)하기 위해 그 체계를 보다 엄격한 도구로 분석하고 모델링해야 한다는 것이다. 본 연구는 이러한 측면에서 움직임 및 스 포츠 체계의 구조적인 특성을 기반으로 네트워크-개인 기전을 구성하고 잠재적인 위험과 이에 대한 보호를 수치 화하기 위한 모형을 다음과 같은 결과로 제시하였다. (a) 시뮬레이션을 통해 근·신경 및 스포츠 네트워크 속성〔방 향성이 없는 무작위 네트워크(random, connectivity, undirected)와 그들의 역학적 상호작용(payoff, failure, and strategy)에 따른 다양성]의 본질을 기술하였다. (b) 각 체계에서 일반적인 위험에 노출된 서로 다른 전략 의 개인 집합을 여러 방향에서 관찰하는데 필요한 전형적 인 실패 영향을 고안하였다. 그리고, (c) 보호 역학이 어 떻게 그 네트워크에서 추정될 수 있는지를 적용하였다. 이는, 모든 스포츠 현장에 잠재하고 있는 실패 및 부상과 같은 체계적 위험이 어떻게 단순한 확률에 의해 다루어질 수 있는지를 특성화한 것이라 할 수 있겠다(Bahrke, 2012).

결과 요약 및 해석: 인위적으로 고안한 본 시뮬레이 션의 부분별 결과가 의미하는 바를 실제 스포츠 현상의 측면에서 주목해보면, 기본적인 모델의 기전은 어떤 문제 
가 있는 개인이 전체 체계를 파괴할 수 있다고 가정한다. 미시적(i.e., cellular, individual) 수준에서 우리의 움 직임은 단순히 신경 명령과 근·골격 (musculoskeletal)의 작용에 의해서만 좌우되지 않는다(Kugler \& Turvey 1987). 거시적 수준(i.e., group, organisations, policitics)에서 스포츠 현상의 다양한 심리/행동적 잠재 변인은 근본적으로 다르게 작용할 수 있는 상호작용과 그 영향력을 따라 창발한다(Rosen, 1987). 다른 효과기를 포함하는 상대성이나 환경에서의 안정성, 지각과 운동 변 수 간의 결합 등과 같은 다양한 비선형적 구조를 포함하 는 대부분의 움직임 및 스포츠 현상이 그러하듯이 매 상 황에서 개인 또는 요소는 체계로서 필수적이고, 모두가 체계의 불안정성을 유발하거나 전체 체계를 붕괴시킬 수 있다(Choi et al., 2004; Narizuka \& Yamazaki, 2018)는 것이다.

구체적으로 단순한 요인의 인과론적 관계보다는 현장 에 내재된 기본 속성과 이를 둘러싼 외부 속성의 체계적 인 접근(systems dynamic)을 통해 매우 다양하고 복잡 한 현상들이 어떤 근본적인 원리에 의해 좌우되는지 (Iberall \& Soodak, 1987) 파악할 수 있도록 한 본 모형 이 반영하는 요점은, 먼저 (i) 전염성 (contagion)을 꼽을 수 있다. 상호 관계하는 스포츠 동작, 경기 또는 산업 구 조와 같이 네트워크에서 한 개인 또는 요소(=vertices) 에 문제가 생기면 그 문제는 연결하고 있는(edge) 그 영 역의 다른 개인 또는 요소에까지 영향을 미치기 때문이 다. 다음으로 (ii) 집중성 (concentration)을 들 수 있다. 사소한 요인 또는 아주 작은 사건일지라도 그 일이 다른 개인 또는 사건보다 많은 주목(centrality)을 받고 있다 (i.e., hub or star player)면 그 파급은 스포츠 현장에서 도 다르게 나타나기 때문이다. 마지막으로 (iii) 맥락 (context)이다. 일반적인 환경에서 일어나는 개인의 기 능이 특정 상황에서 나빠지게 되면 모방과 탐색(social learning)으로 그 맥락의 모든 개인 또는 무리 역시 같은 상황에 빠지기 때문이다. 예를 들어 경기 상황에서 최적 의 성과를 위한 잠재적 요소인 동기(motivation)는 개인 의 능력과 신념의 바탕이 되어 경쟁을 극복할 수 있는 성 취가능성으로 인식시키기도 하지만 두려워 피하게 하는 경향을 유발하기도 한다(Stevenson \& Lochbaum, 2008). 이는 계단식 파급을 일으켜 비단 개인뿐만 아니 라 모방과 학습을 통해 전체 체계로 이어져 팀의 운명을 좌우하기도 하는데(King et al., 2019), 그 정도는 누가
문제를 가졌는가에 따라 달라졌다(Johnson \& Fowler, 2011). 스포츠 기능 또는 현장의 모든 요소 또는 개인은 유사한 방식으로 기능하고 다른 이들과 유사한 위험에 노 출되기 때문에 하나가 넘어지면 그들 모두가 넘어지게 되 는 것이다(Kahneman, 2003).

또 다른 중요한 사실로서 개인의 자본과 실패 간의 분 명한 상관관계(negative)가 나타났고, 아주 작은 확률 또 는 사소한 요인일지라도 위험을 제거하기 위한 투자가 부 재하면 그 맥락의 모두가 시간의 흐름에 따라 기하급수적 으로 실패에 빠지게 되는 것을 관찰하였다. 이러한 결과 에서 중요한 잠재적 요소는 문화적 진화를 통한 모방과 탐색의 딜레마였다. 무작위 확률은 영향력을 조절하고, 그 영향은 인위적으로 고안된 전략 $\left(f_{p 0}\right.$ and $\left.f_{p 1}\right)$ 간 선택 에 달려있는데 이는 각 개인의 모방과 탐색을 통해 이루 어졌기 때문이다(Smith, 2003). 결과는 움직임을 위한 기능적 단위 및 스포츠 조직 내 개인 또는 요소와 이들의 연결 정도로 주어진 중심성이 실패 잠재성에 대한 중요한 동인임을 보여주었고 네트워크에서 축적된 전략의 역동 성은 모방 및 탐색이라는 변인으로써 자세히 검토되었다. 특히, 본 모델과 관련된 진화적 휴리스틱 $\left(f_{p}\right)$ 측정을 통 해, 운동 행동 및 스포츠 체계가 개별 구성원의 행동적 중 심성과 탐색, 그리고 이들의 정규 분포(normal distribution)에 의해 매우 왜곡될 수 있다는 것을 알 수 있었다(Hutchinson \& Gigerenzer, 2005). 인지적 차 이는 행동의 결과 및 해석에 큰 영향(i.e., bias)을 미치기 때문에 개인의 차이를 인식한 규준적인 도구가 설계 및 개발되어야 하는데(Horn, 2015), 이를 위해서는 편견이 없는 합의된 목표가 설정되고 정보가 제공되어야 할 것이 다. 일반 사회뿐만 아니라 스포츠에서도 구체적이고, 투 명하며, 현실적인 정보(i.e., 피드백)는 목표 달성에 대한 성과를 촉진할 수 있음을 발견하고 있다. 예를 들어서, 기 술 혁신과 자동화된 작업 시스템은 좌식 생활 방식을 장 려하고 있지만 다양한 네트워크로 촉진된 건강 관련 아이 디어와 정보의 확산은 예전보다 더 많은 관심을 운동으로 이끌고 있다(Rinehart, 2008). 최근 코로나와 같은 전염 병으로 비롯된 사회적 캠페인은 거리두기(i.e., social distancing, isolation)를 강요하지만 개인을 보호하고 면역 상태를 강화해야 한다는 측면에서 다른 어느 때보다 도 많은 관심을 위생 및 체력에 주목하게 하고 있기도 하 다(World Health Organization, 2020). 사전 연구들에 서 언급되지 않은 조건에 따른 중심성의 영향과 모방 및 
탐색 확률의 정규 분포성은 스포츠 현장의 잠재적인 위험 전파 역학의 강력하고 새로운 속성일 수 있다는 관찰이 다. 이는 서로 다른 전략에 편향된 보호 수준의 영향을 모 방과 상대적인 탐색 비율을 통해 비교해 볼 수 있음을 시 사하고 있기도 할 것이다(Houston et al., 2007).

모형의 적용: 위와 같은 모형의 해석은 다음과 같은 측면에서 스포츠 현장 적용의 시사점을 줄 수 있을 것으 로 사료한다. 첫째, 다양한 형태와 척도로 구성되어있는 매우 복잡한 체계(Davids et al., 1994)로서 스포츠에 참여하는 우리는 내적 요동(perturbation), 외적 영향 (influence)과 중재(intervention)에 대한 반응으로 끊 임없이 학습하며 지속적인 재구성을 이룬다(Pain \& Harwood, 2007). 따라서 이러한 현상을 일으키는 요소 의 유형, 빈도, 강도 및 기간 등을 더 정확하게 이해하기 위해서는 일차원적인 확률로서 각 개인의 내적 수준뿐 아 니라 매개변수로서 영향을 행사하는 외부조건, 연결, 유 발전략 등의 다차원적인 체계 접근이 필요하다. 본 모형 은 스포츠 현상의 다양한 변화는 물론, 일상생활, 선호하 는 습관, 전문적인 의무 및 스트레스 요인 등 개별 질적/ 양적 변인을 포함하여, 이로 인한 재구성을 관찰할 수 있 게 할 것이다(Casey et al., 2012). 둘째, 위와 같이 잠재 성의 경계를 지속해서 업그레이드하는 스포츠 현상은 자 기조직적이다(Latash et al., 2007). 자기조직체계 고유 속성의 측면에서 유기체는 오류를 최소화하고 평형 (equilibrium)을 유지하기 위해 적절한 적응을 스스로 이루지만(Kugler et al., 1980), 복잡계의 특성상 초기 상태 또는 갑작스러운 전이로 인해 체계의 큰 문제가 발 생할 수 있는데 본 모형은 이러한 측면을 포함 시킬 수 있 을 것이다. 셋째, 이렇게 초기 상태 또는 작은 요인이 큰 영향(Bahrke, 2012)을 미칠 수 있는 스포츠의 다차원적 인 결과 및 현상은 창발(emergent properties)이라는 특 질로 정의되곤 한다(Vilar et al., 2013). 일례로, 우리가 흔히 목격하는 실패 또는 부상은 개인과 과제, 그리고 환 경적 요인의 복합적인 결과로서 언제나 불확실한 잠재성 이다. 따라서, 스포츠 과학자들이 실제로 이러한 위험을 예측하려면, 복잡한 여러 수준에서 지속적으로 적응하고 진화하는 체계 접근이 필요하다는 사실을 상기해야 한다 (Dunning, 1999). 본 모형은 스포츠의 다양한 요인 간 복잡한 상호작용으로 인해 발생하는 창발 현상을 체계적 으로 관찰할 수 있게 할 것이다. 다양한 스포츠 시스템의
모든 입력과 출력을 식별하기는 어렵지만, 현상의 원인이 무엇인지? 예방의 열쇠는 무엇일지? 라는 자체의 물음에 본 모형에서 구체화하고 있는 계산 모델링은 비선형적인 요인과 그들의 상호작용을 조사하고 이해하는 것을 가능 하게 할 수 있을 것으로 생각한다.

결론 및 제언: 1971년 소개된 단순한 시뮬레이션은 스스로 상호 작용하는 개별 의사결정 및 행동 양상을 모 형으로 구현함으로써 과학의 기초를 이루는 중요한 문제 를 다루어 주었다(Schelling, 1971). 개인별로 구분되는 행 동의 기준이 무엇인지, 집단을 구성하는 기초가 무엇인 지, 나아가서 그들을 유지/관리하기 위해 가장 적합한 전 략은 무엇인지에 대한 통찰을 제공하였다. 이러한 맥락에 서 본 모형은 조작적으로 정의한 근·신경 또는 스포츠라 는 체계내에서 시간이 지남에 따라 다르게 상호작용하는 개인을 시뮬레이션 하였다. 잘 프로그래밍 된 모형에서 개인 간의 상향식(bottom-up) 상호작용이 복잡한 현상 으로 이어질 방법에 대한 통찰을 제공하는 것과 같이 본 연구에서는 개념적으로 쉽게 이해를 돕기 위해 기전 및 전개 과정을 가시화하였으며, 가능한 단순한 원리에 근거 하여 개인의 창발 행동 및 전략을 탐색 할 수 있도록 하였 다. 또한, 실질적인 체계적 주제 (failure or protection potential)에 대한 규칙과 과정을 역학적으로 적용함으 로써 스포츠 과학 연구에 필요한 통찰은 물론 잠재적인 모형을 스스로 구축해 보는데 유용한 안내를 하고 있다. 다양한 영역에서 보고하고 있는 경험에 따른 상호 관 계 네트워크 결과들은 보수(incentive)와 수행성능 (fitness)이 중요하다고 의견(Noteboom, 2002)을 내놓 지만, 네트워크 역동성의 전체 내용을 이야기하기보다는 부분적인 확인만 보고(Gilsing, et al., 2008)하고 있었 다. 이에, 근·신경 및 스포츠의 무작위한 네트워크-개인 구조를 통해 본 모형에서 제안한 “보호 역학”은 실질적으 로 실패에서 벗어나는 잠재적 위험 요소의 재구조를 이루 어낼 수 있다는 것을 암시하였으며, 시간에 따라 다르게 나타나는 네트워크 요소(incentive = payoff, fitness $=$ $\left.f_{p}\right)$ 의 관계, 감독 및 구조 $\left(p_{p}\right)$ 가 어떻게 작용하는지에 관한 질문에 답하기 위해 불확실성의 비판적인 검사 (Hoang \& Antoncic, 2003)를 가시화하였다. 단순하지 만 근본적인 이러한 관찰은 다음과 같은 유용성과 함의를 갖는 하나의 지표로서 역할을 할 수 있을 것으로 생각한다. 첫째, (i) 비교적 쉽고 간단하게 스포츠(과학) 영역에 
서 체계적 위험을 측정하고 이의 발생 가능성에 대한 정 보를 제공할 수 있는 전형이 될 수 있을 것이다. 이는 거 시적인 수준에서 체계의 구조와 그 변화를 파악하는 데 유용하게 활용될 수 있음을 의미하기도 한다. 다음으로 (ii) 개별 요소 간 잠재적인 위험이 전파하는 경로와 과정 을 추정할 수 있을 것이다. 이는 지도나 감독 등의 측면에 서 체계적인 전략을 수립하는데 중요한 요소로서 작용할 수 있을 것이다. 마지막으로 (iii) 미시적인 수준에서 체 계를 구성하는 주체 (근.신경, 개인, 팀, 구단 등) 간 상호 연계성 및 위험의 전파 양상을 파악하도록 할 수 있을 것 이다. 이는 거시적 수준의 정책 수립으로 확대 및 적용될 수 있고, 구현된 규칙과 계산적 과정은 의사결정자들이 역동적인 체계적 위험에 대한 조금 더 발전적인 시각을 얻을 수 있게 해 줄 것이다.

네트워크-개인 기반 모형은 주목할 만한 많은 발견을 내어놓았다(Helbing, 2013; Vespignani, 2018). 특히, 체계 역학과 관련한 연구에서 바람직한 체계는 실제로 모 든 대상의 균형을 필요로 하는데, 본 모형에서도 강조된 이 일반성은 복잡한 움직임 및 스포츠 현상에서도 비단 다르지 않을 것으로 생각한다. 간단히 두 가지 전략 (failure or absence of failure)으로만 구성된 본 모델의 기전을 바탕으로 체계적 위험의 추후 연구를 위한 흥미로 운 방향의 동기가 부여될 수 있기를 희망한다. 더 많은 유 형의 구조와 개인 (Quatman \& Chelladurai, 2008), 방 향성, 실제 현장 자료를 기반으로 한 인과관계 등 보다 현 실적이고 상세한 분석으로 확대된다면, 최적의 전략 또는 의사결정의 측면에서 스포츠 현상의 잠재적인 위험과 관 계된 문제들을 보다 효율적으로 다루기 위한 전망을 향상 시킬 수 있을 것이다(Fortunato, 2010).

\section{참고문헌}

Abbott, A. (1988). Transcending general linear reality. Sociological theory, 6(2), 169-186.

Bahrke, M. S. (2012). Performance-enhancing substance misuse in sport: Risk factors and considerations for success and failure in intervention programs. Substance Use \& Misuse, 47(13-14), 1505-1516.

Barabási, A. L., \& Albert, R. (1999). Emergence of scaling in random networks. science, 286(5439), 509-512.
Beer, R. D. (1995). A dynamical systems perspective on agent-environment interaction. Artificial Intelligence, 72(1), 173-215.

Bernstein, N. (1967). The co-ordination and regulation of movements. Pergamon Press, Oxford

Bittencourt, N. F. N., Meeuwisse, W. H., Mendonça, L. D., Nettel-Aguirre, A., Ocarino, J. M., \& Fonseca, S. T. (2016). Complex systems approach for sports injuries: moving from risk factor identification to injury pattern recognitionnarrative review and new concept. British journal of sports medicine, 50(21), 1309-1314.

Bjørnstad, O. N., Finkenstädt, B. F., \& Grenfell, B. T. (2002). Dynamics of measles epidemics: estimating scaling of transmission rates using a time series SIR model. Ecological monographs, 72(2), 169-184.

Bohm, D. (1969). Some remarks on the notion of order. In C. H. Waddington (Ed.), Towards a theoretical biology, Volume 2 (pp. 18-40). Chicago: Aldine Publishing Company.

Bonabeau, E. (2002). Agent-based modeling: Methods and techniques for simulating human systems. Proceedings of the National Academy of Sciences, 99 (suppl. 3), 7280-7287.

Boza, G., Worsley, S. F., Douglas, W. Y., \& Scheuring, I. (2019). Efficient assembly and long-term stability of defensive microbiomes via private resources and community bistability. PLoS computational biology, 15(5), e1007109.

Bruch, E., \& Atwell, J. (2015). Agent-based models in empirical social research. Sociological Methods \& Research, 44(2), 186-221.

Casey, M. M., Payne, W. R., \& Eime, R. M. (2012). Organisational readiness and capacity building strategies of sporting organisations to promote health. Sport management review, 15(1), 109-124.

Cassidy, T. G., Jones, R. L., \& Potrac, P. (2008). Understanding sports coaching: The social, cultural and pedagogical foundations of coaching practice. Routledge.

Cederman, L. E. (2005). Computational models of social forms: Advancing generative process theory. American Journal of Sociology, 110(4), 864-893.

Choi, S. B., Kang, C. W., Choi, H. J., \& Kang, B. Y. (2011). Social network analysis for a soccer game. Journal of the Korean Data and Information Science Society, 22(6), 1053-1063.

Clemente, F. M., Martins, F. M. L., \& Mendes, R. S. (2016). Social network analysis applied to team sports analysis. Netherlands: Springer International Publishing.

Colander, D., Föllmer, H., Haas, A., Goldberg, M. D., Juselius, K., 
Kirman, A., ... \& Sloth, B. (2009). The financial crisis and the systemic failure of academic economics. Univ. of Copenhagen Dept. of Economics Discussion Paper, (09-03).

Collins, J. J., \& Stewart, I. N. (1993). Coupled nonlinear oscillators and the symmetries of animal gaits. Journal of Nonlinear science, 3, 349-392.

Davids, K., Handford, C., \& Williams, M. (1994). The natural physical alternative to cognitive theories of motor behaviour: An invitation for interdisciplinary research in sports science? Journal of sports Sciences, 12(6), 495-528.

Dehmamy, N., Milanlouei, S., \& Barabási, A. L. (2018). A structural transition in physical networks. Nature, 563(7733), 676.

Dunning, E. (1999). Sport matters: Sociological studies of sport, violence, and civilization. Psychology Press.

El-Sayed, A. M., \& Galea, S. (Eds.). (2017). Systems science and population health. Oxford University Press.

Erdos, P., \& Rényi, A. (1959). On Cantor's series with convergent $\sum$ 1/qn. Ann. Univ. Sci. Budapest. Eötvös. Sect. Math, 2, 93-109.

Fawcett, T. W., Fallenstein, B., Higginson, A. D., Houston, A. I., Mallpress, D. E., Trimmer, P. C., \& McNamara, J. M. (2014). The evolution of decision rules in complex environments. Trends in cognitive sciences, 18(3), 153-161.

Fawcett, T. W., Hamblin, S., \& Giraldeau, L. A. (2012). Exposing the behavioral gambit: the evolution of learning and decision rules. Behavioral Ecology, 24(1), 2-11.

Forgas, J. P. (1995). Mood and judgment: The affect infusion model (AIM). Psychological Bulletin, 117(1), 39.

Fortunato, S. (2010). Community detection in graphs. Physics reports, 486(3-5), 75-174.

Gilsing, V., Nooteboom, B., Vanhaverbeke, W., Duysters, G., \& van den Oord, A. (2008). Network embeddedness and the exploration of novel technologies: Technological distance, betweenness centrality and density. Research policy, 37(10), 1717-1731.

Goldstone, R. L., \& Janssen, M. A. (2005). Computational models of collective behavior. Trends in cognitive sciences, 9(9), 424-430.

Gréhaigne, J. F., Godbout, P., \& Bouthier, D. (2001). The teaching and learning of decision making in team sports. Quest, 53(1), 59-76.

Grillner, S. (1975). Locomotion in vertebrates: Central mechanisms and reflex interaction. Physiological Reviews, 55, 247-304.

Grove, J. R., Hanrahan, S. J., \& McInman, A. (1991).
Success/failure bias in attributions across involvement categories in sport. Personality and Social Psychology Bulletin, 17(1), 93-97.

Guardiola, X., Guimera, R., Arenas, A., Diaz-Guilera, A., Streib, D., \& Amaral, L. A. N. (2002). Macro-and micro-structure of trust networks. arXiv preprint cond-mat/0206240.

Haken, H. (2012). Advanced synergetics: instability hierarchies of self-organizing systems and devices. Springer, Berlin.

Hajihashemi, M., \& Samani, K. A. (2019). Fixation time in evolutionary graphs: Amean-field approach. Physical Review E, 99(4), 042304.

Helbing, D. (2013). Globally networked risks and how to respond. Nature, 497(7447), 51.

Hoang, H., \& Antoncic, B. (2003). Network-based research in entrepreneurship: A critical review. Journal of business venturing, 18(2), 165-187.

Horn, T. S. (2015). Social psychological and developmental perspectives on early sport specialization. Kinesiology Review, 4, $248-266$.

Horn, T. S., \& Newton, J.L. (2019). Developmentally based perspectives on motivated behavior in sport and physical activity contexts. In T.S. Horn \& A.L. Smith (Eds.), Advances in sport and exercise psychology (4th ed., pp. 313 -331). Champaign, IL: Human Kinetics.

Houston, A. I., McNamara, J. M., \& Steer, M. D. (2007). Do we expect natural selection to produce rational behaviour? Philosophical Transactions of the Royal Society B: Biological Sciences, 362(1485), 1531.

Hulme, A., Thompson, J., Nielsen, R. O., Read, G. J., \& Salmon, P. M. (2019). Towards a complex systems approach in sports injury research: simulating running-related injury development with agent-based modelling. Br J Sports Med, 53(9), 560-569.

Hulme, A., \& Finch, C. F. (2015). From monocausality to systems thinking: a complementary and alternative conceptual approach for better understanding the development and prevention of sports injury. Injury epidemiology, 2(1), 1-12.

Hutchinson, J. M., \& Gigerenzer, G. (2005). Simple heuristics and rules of thumb: Where psychologists and behavioural biologists might meet. Behavioural processes, 69(2), 97-124.

Iberall, A. S., \& Soodak, H. (1987). A physics for complex systems. In Self-organizing systems (pp. 499-520). Springer US.

Jackson, J. C., Rand, D., Lewis, K., Norton, M. I., \& Gray, K. (2017). Agent-based modeling: A guide for social psychologists. Social Psychological and Personality Science, 
8(4), 387-395.

Jarvie, G. (2013). Sport, culture and society: an introduction. Routledge.

Johnson, D. D., \& Fowler, J. H. (2011). The evolution of overconfidence. Nature, 477(7364), 317.

Kahneman, D. (2003). A perspective on judgment and choice: mapping bounded rationality. American psychologist, 58(9), 697.

King, A. C., Whitt-Glover, M. C., Marquez, D. X., Buman, M. P., Napolitano, M. A., Jakicic, J., ... \& Tennant, B. L. (2019). Physical activity promotion: highlights from the 2018 physical activity guidelines advisory committee systematic review. Medicine \& Science in Sports \& Exercise, 51(6), 1340-1353.

Kugler PN, Kelso JS, Turvey MT. (1980). On the concept of coordinative structures as dissipative structures: I. Theoretical lines of convergence. Adv Psychol 1:3 - 47.

Kugler, P. N., \& Turvey, M. T. (1987). Information, natural law and the self-assembly of rhythmic movement. Hillsdale, NJ: Erlbaum.

Latash, M. L., Scholz, J. P., \& Schöner, G. (2007). Toward a new theory of motor synergies. Motor control, 11(3), 276-308.

Leduc, M., Poledna, S., \& Thurner, S. (2017). Systemic risk management in financial networks with credit default swaps.

Lewis, K. (2015). Three fallacies of digital footprints. Big Data \& Society, 2(2), 1-4.

Lin, N. (2017). Building a network theory of social capital. In Social capital (pp. 3-28). Routledge.

Lusher, D., Robins, G., \& Kremer, P. (2010). The application of social network analysis to team sports. Measurement in physical education and exercise science, 14(4), 211-224.

Marshall, J. A., Trimmer, P. C., Houston, A. I., \& McNamara, J. M. (2013). On evolutionary explanations of cognitive biases. Trends in ecology \& evolution, 28(8), 469-473.

Miller, N. E., \& Dollard, J. (1941). Social learning and imitation, (Yale University, New haven, 1941).

Moody, J. (2004). The structure of a social science collaboration network: Disciplinary cohesion from 1963 to 1999. American sociological review, 69(2), 213-238.

Narizuka, T., \& Yamazaki, Y. (2018). Characterization of the formation structure in team sports. arXiv preprint arXiv:1802.06766.

Newell, K. M., \& Ranganathan, R. (2010). Instructions as constraints in motor skill acquisition. In Motor learning in practice (pp. 37-52). Routledge.

Noteboom, B. (2002). Forms of trust. Trust; Forms, Foundations,
Functions, Failures and Figures, Cheltenham, Northampton, 36-54.

Oliva, R. (2016). Structural dominance analysis of large and stochastic models. System dynamics review, 32, 26-51.

Pacheco, J. M., Traulsen, A., \& Nowak, M. A. (2006). Coevolution of strategy and structure in complex networks with dynamical linking. Physical review letters, 97(25), 258103.

Pain, M. A., \& Harwood, C. (2007). The performance environment of the England youth soccer teams. Journal of Sports Sciences, 25(12), 1307-1324.

Park, C. (2018). Biological autonomy and control of function in circadian cycle. Korean Journal of Sport Science, 29(3), 443-455.

Park, C. (2020). Evolutionary understanding of the conditions leading to estimation of behavioral properties through system dynamics. Complex Adaptive Systems Modeling, 8(1), 2.

Park, C. (2020). Network and Agent Dynamics with Evolving Protection against Systemic Risk. Complexity, 2020.

Pastor-Satorras, R., Castellano, C., Van Mieghem, P., \& Vespignani, A. (2015). Epidemic processes in complex networks. Reviews of modern physics, 87(3), 925.

Powell, W. W., White, D. R., Koput, K. W., \& Owen-Smith, J. (2005). Network dynamics and field evolution: The growth of interorganizational collaboration in the life sciences. American journal of sociology, 110(4), 1132-1205.

Putnam, R. D. (2000). Bowling alone: America's declining social capital. In Culture and politics (pp. 223-234). Palgrave Macmillan, New York.

Purves, D., Augustine, G. J., Fitzpatrick, D., Katz, L. C., Lamantia, A. S., McNamara, J. O., \& Williams, S. M. (2001). Neuroscience. 2nd. Sunderland: Sinauer.

Quatman, C., \& Chelladurai, P. (2008). The social construction of knowledge in the field of sport management: A social network perspective. Journal of Sport Management, 22(6), 651-676.

Railsback, S. F., \& Grimm, V. (2019). Agent-based and individual-based modeling: a practical introduction. Princeton university press.

Reynolds, C. W. (1987). Flocks, herds and schools: A distributed behavioral model. In ACM SIGGRAPH computer graphics, 21, 25-34.

Ribeiro, J., Silva, P., Duarte, R., Davids, K., \& Garganta, J. (2017). Team sports performance analysed through the lens of social network theory: implications for research and practice. Sports medicine, 47(9), 1689-1696.

Rinehart, R. E. (2008). Exploiting a new generation. Youth culture 
and sport: Identity, power, and politics, 71.

Robins, G., Pattison, P., Kalish, Y., \& Lusher, D. (2007). An introduction to exponential random graph $\left(\mathrm{p}^{*}\right)$ models for social networks. Social networks, 29(2), 173-191.

Rosen, R. (1987). Some epistemological issues in physics and biology. In B. J. Hilley \& F. D. Platt (Eds.), Quantum implications: Essays in honor of David Bohm (pp. 315-327). New York: Routlege \& Kegan.

Rosen, S., \& Sanderson, A. (2001). Labour markets in professional sports. The economic journal, 111(469), F47-F68.

Schelling, T. C. (1971). Dynamic models of segregation. Journal of Mathematical Sociology, 1(2), 143-186.

Shariff, A. F., Willard, A. K., Andersen, T., \& Norenzayan, A. (2016). Religious priming a meta-analysis with a focus on prosociality. Personality and Social Psychology Review, 20(1), $27-48$.

Shoham, D. A., Tong, L., Lamberson, P. J., Auchincloss, A. H., Zhang, J., Dugas, L., ... \& Luke, A. (2012). An actor-based model of social network influence on adolescent body size, screen time, and playing sports. PloS one, 7(6), e39795.

Sigmund, K., \& Nowak, M. A. (1999). Evolutionary game theory. Current Biology, 9(14), R503-R505.

Smith, A. L. (2003). Peer relationships in physical activity contexts: A road less traveled in youth sport and exercise psychology research. Psychology of sport and Exercise, 4(1), 25-39.

Stevenson, S. J., \& Lochbaum, M. R. (2008). Understanding Exercise Motivation: Examining the Revised Social-Cognitive Model of Achievement Motivation. Journal of Sport Behavior, 31(4).

Sussillo, D., Churchland, M. M., Kaufman, M. T., \& Shenoy, K. V. (2015). A neural network that finds a naturalistic solution for the production of muscle activity. Nature neuroscience, 18(7), 1025-1033.
Tesfatsion, L., \& Judd, K. L. (Eds.). (2006). Handbook of computational economics: agent-based computational economics (Vol. 2). Amsterdam: Elsevier.

Thacker, S. B., Stroup, D. F., Branche, C. M., \& Gilchrist, J. (2003). Prevention of knee injuries in sports: A systemic review of the literature. Journal of Sports Medicine and Physical Fitness, 43(2), 165.

Trimmer, P. C., Houston, A. I., Marshall, J. A., Mendl, M. T., Paul, E. S., \& McNamara, J. M. (2011). Decision-making under uncertainty: biases and Bayesians. Animal cognition, 14(4), 465-476.

Turvey, M. T., Fonseca, S. T., \& Sternad, D. (2008). Progress in motor control: A multidisciplinary perspective. Progress in motor control: A multidisciplinary perspective.

Tversky, A., \& Kahneman, D. (1985). The framing of decisions and the psychology of choice. In Environmental Impact Assessment, Technology Assessment, and Risk Analysis (pp. 107-129). Springer Berlin Heidelberg.

Vespignani, A. (2018). Twenty years of network science. Nature, 558(528 - 529), 10

Vilar, L., Araújo, D., Davids, K., \& Bar-Yam, Y. (2013). Science of winning soccer: Emergent pattern-forming dynamics in association football. Journal of systems science and complexity, 26(1), 73-84.

World Health Organization. (2020). Coronavirus disease 2019 (COVID-19): situation report, 72.

Wooldridge, J. M. (2003). Cluster-sample methods in applied econometrics. The American Economic Review, 93(2), 133-138. 


\title{
네트워크-에이전트 체계 역학 모형; 스포츠 과학을 위한 안내
}

\author{
박철욱 ${ }^{1}$, 김선진 ${ }^{2}$ \\ ${ }^{1}$ 서울대학교 스포츠과학연구소 객원교수 \\ ${ }^{2}$ 서울대학교 스포츠과학연구소 교수
}

〔목적〕 본 연구는 네트워크-에이전트 기반 구조를 바탕으로 체계적 잠재성의 원리 및 모형을 소개하고 스포 츠과학을 위한 적용 가능성을 시사하고자 하는 데 목적을 두고 있다. (방법) 이를 위해 스포츠의 구조적 특성 을 잘 대변하는 것으로 알려진 무작위 네트워크(random graph) 알고리즘에 이미 다양한 분야에서 활발히 적용되고 있는 개인 기반 모델(Agent-based model)과 보수(payoff), 실패(failure), 전략(strategy) 역학 을 적용함으로써 큰 사건의 원인으로 인식되고 있는 체계적 잠재성 확산 및 이에 대한 기전을 프로그래밍하였 다. 〔결과〕 컴퓨터 모의 시뮬레이션 결과 실패와 같은 잠재적 위험 요소의 확산은 각 개인이 형성하는 네트워 크의 기본적인 특성에 의해 결정되었다. 하지만 이러한 위험의 일반적 잠재성에도 불구하고 모방 및 탐색을 통한 각 개인의 진화적(비진화적) 매개변수들은 보호의 점진적 가능성을 발견적으로 일으키기도 하였다. ‘결 론] 많은 현장에서 진화론적 적합성에 기반한 체계적 잠재성 분석 및 관리의 방법론적 기전을 구축하는 모형을 찾고 있음을 참작할 때 본 모형은 스포츠 과학 분야에서 유용한 개념적/기법적 영감을 일으킬 수 있을 것으로 생각한다.

주요어: 무작위 네트워크, 개인-기반 모델, 체계 역학, 위험, 휴리스틱 